\title{
Incentivising the Social Discounting Task: A laboratory experiment
}

\author{
Frederik Booysen \\ Tshepo Moloi \\ Alistair Munro \\ Sevias Guvuriro \\ Celeste Campher
}

January 2017

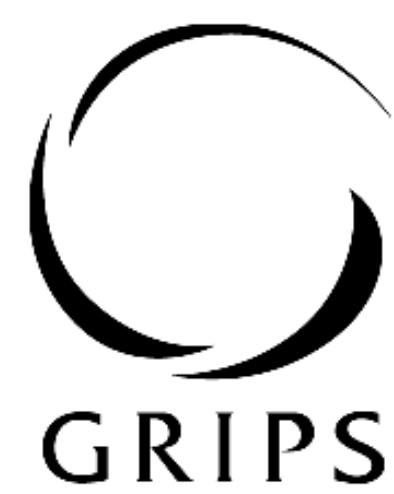

National GRADUATE InStitute FOR POLICY STUDIES

National Graduate Institute for Policy Studies

7-22-1 Roppongi, Minato-ku,

Tokyo, Japan 106-8677 


\title{
Incentivising the Social Discounting Task: A laboratory experiment
}

\author{
Booysen, F. ${ }^{1}$, Moloi, T. ${ }^{1}$, Munro, A. ${ }^{2}$, Guvuriro, S. ${ }^{1}$, Campher, C. ${ }^{1}$
}

[26 January 2017]

\begin{abstract}
Altruism is one of the single most important social preferences driving human behaviour. In Psychology experiments, the Social Discounting Task is employed as a measure of altruism. A conventional laboratory experiment was conducted with 117 undergraduate students, with students randomly assigned to complete an incentivized and un-incentivized Social Discounting Task. In accordance with the 1/d law of giving, the results exhibit the expected inverse relationship between social distance and altruism. There is weak evidence that incentivizing the Social Discounting Task impacts the measurement of altruism in a student population. More specifically, subjects are more altruistic when incentivized, possibly due to enforced reciprocity. At the same time, making payments real influence the identity of the target recipients: paying makes subjects more likely to choose people who are physically and psychologically close at high ranks, and more likely to report greater physical and psychological distance to subjects at lower ranks. Further research is required to verify the robustness of this result. The study also shows that among students family members are more altruistic toward each other as are those exhibiting greater intergenerational solidarity. Preferences for altruism in this student population is no different from WEIRD subject populations.
\end{abstract}

JEL codes: C91, D64

Keywords: experiment, Social Discounting Task (SDT), social distance, family, South Africa

Acknowledgement: This work was supported financially by the National Graduate Institute for Policy Studies (GRIPS), Japan (H26-GRIPS-PRC-01) and the DST-NRF Centre of Excellence in Human Development, South Africa (NO 96132).

\footnotetext{
${ }^{1}$ Department of Economics, University of the Free State (UFS), Bloemfontein, South Africa.

${ }^{2}$ National Graduate Institute for Policy Studies (GRIPS), Tokyo, Japan.
} 


\section{Introduction}

In the social discounting task (SDT) that is often used in experimental psychology to examine patterns of altruism, subjects identify individuals at different social distances and play a linked series of modified dictator games against the nominee at each social distance. In a typical experiment (e.g. Olson et al., 2016; Rachlin \& Locey, 2011) subjects are asked to nominate specific individuals at particular social distances from 1 to 100 . For instance, \#1 might be a parent or a spouse, \#5 might be a close friend and so on. For each of the nominees, subjects make a series of bilateral choices between money for themselves and money for the other person. The questions are structured so that there is a clear trend in the sums of money and the choice at which the subject switches from a sum for themselves to a sum for the other person is used to construct a measure of how altruistic feelings fall as potential partners become more socially distant.

Typically, payments are hypothetical in a SDT experiment. In fact in the approximately twenty-five experiments on social discounting conducted to date, few employ real payments. ${ }^{3}$ The exceptions are Locey, Jones and Rachlin (2011) who execute one randomly chosen task for payment and the recent work by Strombach et al. (2014/2015/2016) who also choose one task at random, though they pay only $10 \%$ of the face value of amounts used in the actual experiment. ${ }^{4}$ Economists are largely sceptical of the value of experiments in which no real payments are made (Hertwig and Ortmann, 2001) and even within the SDT literature, Yi, Carter and Landes (2012), recognise the limitation of the widespread use of hypothetical incentives in social discounting experiments. Making payments real might affect the apparent weight that subjects place on money received by recipients. In addition, in the standard protocol for an SDT the subject nominates the recipient shortly before making their choices. As a result, having real payments may also change the set of people who are nominated, an issue that has not been examined in the few studies that do have real payments. ${ }^{5}$ One reason why the set may change depending on payment rules is related to the reason why real payments may change the level of payment. When payments are hypothetical the theoretical

\footnotetext{
${ }^{3}$ Experiments considered for inclusion in the literature review represent those that not only administered a social discounting task (SDT) to subjects, but analysed the resultant data - examples of studies that do not apply any quantitative analysis to the social discounting data include Liu et al. (2015) and Safin, Arfer and Rachlin (2015).

${ }^{4}$ To be clear, subjects are informed that this will be the case.

${ }^{5}$ Strombach et al. $(2014,2015,2016)$ only have a real payment treatment. Locey et al. (2011) have both hypothetical and real payment treatments, but depart from the typical practice of SDT tasks by asking subjects to pre-nominate recipients. While this means that their analysis can focus on the pure effect of real payments on the switching point, it means that they cannot analyse whether, in the typical SDT experiment, the set of recipients is affected by the hypothetical nature of the task.
} 
recipient never has a reason to think they have been the object of an experiment and that someone made a decision about giving them money. However, when payments are real the recipient may receive money and in this case she or he may be able to identify the donor even if this information is not formally given out. Anticipating this possibility, the experimental subject may wish to be generous (to avoid social embarrassment for example, or because there is some possibility of future reciprocity). At the same time, the subject faced with the possibility of real payment may choose their target recipient in a different way when payments are real. They may, for instance, choose someone who is more likely to reciprocate or someone with whom they would not feel social embarrassment at giving little.

Apart from the hypothetical nature of payments, another fact that can influence behaviour in a SDT task is the pattern of human relationships in a particular country. In particular, preferences, and in this case social discounting, may be quite different in a society governed by a more collectivist culture in which the wider family and other social networks play an important role. This point has been made quite forcefully for social science experiments in general by Henrich, Heine and Norenzayan (2010) who emphasize that the overwhelming majority of social psychology (and economics) experimental data comes from subjects who are "WEIRD", i.e. from a Western, Educated, Industrialised, Rich, and Democratic country. In keeping with the typical pattern of social psychology experiments, most SDT research has been conducted within "WEIRD” environments.

So, the contribution of this research is that it investigates the extent to which using real payments in the Social Discounting Task matters for the measurement of altruism, both in terms of the level of measured altruism and also in the set of recipients. It does so in a location outside the usual WEIRD setting. A related objective of the paper is to investigate the role of specific sender and recipient characteristics in explaining differences in observed inter-personal altruism, including the role of family relations and other social dynamics.

The paper is structured as follows: Section 2 presents a brief overview of the empirical literature, while Section 3 and 4 describes the experimental task and methods of analysis, respectively. Section 5 contains the results and their discussion. Section 6 concludes. 


\section{Box 1: Social discounting experiments}

Böckler, A., Tusche, A. \& Singer, T. (2016) The Structure of Human Prosociality: Differentiating Altruistically Motivated, Norm Motivated, Strategically Motivated, and Self-Reported Prosocial Behavior. Social Psychological and Personality Science, (online): 1-12.

Boyer, P., Lienard, P. \& Xu, J. (2012) Cultural Differences in investing in others and in the Future: Why Measuring Trust is not Enough. PLoS ONE, 7(7): e40750.

Bradstreet, M. P., Higgins, S.T., Heil, S.H., Adger, G.J.B., Kelly, J.M.S., Lynch, M.E. \& Trayah, M.C. (2012) Social Discounting and Cigarette Smoking During Pregnancy. Journal of Behavioral Decision-Making, 25: 502-511.

He, G. \& Jiang, D. (2013) The effect of task frames and altruism on social discounting. Acta Psychologica Sinica, 45(10): 1131-1146.

Ito, M., Saeki, D. \& Green, L. (2011) Sharing, Discounting, and Selfishness: A Japanese-American Comparison. Psychological Record, 60: 5976

Jones, B. \& Rachlin, H. (2006) Social Discounting. Psychological Science, 17(4): 283-286.

Jones, B. \& Rachlin, H. (2009) Delay, Probability, and Social Discounting in a Public Goods Game. Journal of the Experimental Analysis of Behaviour, 91: 61-73.

Kaplan, B.A., Reed, D.D. \& McKerchar, T.L. (2014) Using a visual analogue scale to assess delay, social and probability discounting of an environmental loss. Psychological Record, 64: 261-269.

Locey, M.L, Jones, B. \& Rachlin, H. (2011) Real and hypothetical rewards. Judgment and Decision Making, 6(6): $552-564$.

Locey, M.L., Safin, V. \& Rachlin, H. (2013) Social Discounting and the Prisoner's Dilemma Game. Journal for Experimental Analysis of Behaviour, 99(1): 85-97.

Locey, M.L. \& Rachlin, H. (2015) Altruism and anonymity: A behavioural analysis. Behavioural Processes, 118: 71-75.

Luhmann, C.C. \& Pak, S. S. (2013) Won't You Think of the Children?: Traits Predicting Intergenerational Preferences. In M. Knauff, M. Pauen, N. Sebanz, \& I. Wachsmuth (Eds.), Proceedings of the 35th Annual Conference of the Cognitive Science Society (pp. 2949-2954). Austin, TX: Cognitive Science Society.

Olson, E.A., Rosso, I.M., Demers, L.A., Divatia, S. \& Killgore, W.D.S. (2016) Sex Differences in Psychological Factors Associated with Social Discounting. Journal of Behavioral Decision Making, 29: 60-66.

Osiński, J. (2009) Kin altruism, reciprocal altruism and social discounting. Personality and Individual Differences, 47: 374-378.

Osiński, J. (2010) Social Discounting: The effect of outcome uncertainty. Behavioural Processes, 85: 24-27.

Osiński, J., Karbowski, A. \& Ostaszewski, P. (2015) Social Discounting: Choice between rewards for other people. Behavioural Processes, 115: 61-63.

Rachlin, H. \& Jones, B.A. (2008a) Altruism among relatives and non-relatives. Behavioural Processes, 79: 120-123.

Rachlin, H. \& Jones, B.A. (2008b) Social Discounting and Delay Discounting. Journal of Behavioral Decision Making, 21: 29-43.

Sharp, C., Barr, G., Ross, D., Bhimani, R., Ha, C. \& Vuchinich, R. (2012) Social Discounting and Externalizing Behavior Problems in Boys. Journal of Behavioral Decision-Making, 25: 239-247.

Strombach, T., Jin, J., Weber, B., Kenning, P., Shen, Q., Ma, Q. \& Kalenscher, T. (2013) Charity Begins at Home: Cultural Differences in Social Discounting and Generosity. Journal of Behavioral Decision Making, 27(3): 235-245.

Strombach, T., Margittai, Z., Gorczyca, B. \& Kalenscher, T. (2016) Gender-Specific Effects of Cognitive Load on Social Discounting. PLoS ONE, 11(10): e0165289.

Strombach, T., Weber, B., Hangebrauk, Z., Kenning, P., Karipidis, I.I., Tobler, P.N. \& Kalenscher, T. (2015) Social discounting involves modulation of neural value signals by temporoparietal junction. PNAS, 112(5): 1619-1624.

Yi, R., Carter, A.E. \& Landes, R.D. (2012) Restricted psychological horizon in active methamphetamine users: future, past, probability and social discounting. Behavioural Pharmacology, 23: 358-366.

Yi, R., Charlton, S., Porter, C., Carter, A.E. \& Bickel, W.K. (2011) Future altruism: Social discounting and delayed rewards. Behavioural Processes, 86: 160-163

Yi, R., Pickover, A., Stuppy-Sullivan, A.M., Baker, S. \& Landes, R.D. (2016) Impact of episodic thinking on altruism. Journal of Experimental Social Psychology, 65: 74-81.

Ziegler, F.V. \& Tunney, R.J. (2012) Decisions for Others Become Less Impulsive the Further Away They Are on the Family Tree. PlosONE, 7(11): e49479. 


\section{Literature review}

With social discounting tasks in some ways being comparable to a dictator game (i.e. a choice is made between money for oneself and money for someone else in a two-person economic game), it is important to at the outset make reference to the literature on dictator giving and social distance. ${ }^{6}$ Empirically, researchers have mimicked social distance by experimentally inducing differences in the degree of anonymity between dictator and recipient (Bechler, Green \& Myerson, 2015; Bohnet \& Frey, 1999; Charness \& Gneezy, 2008; Hoffman, McCabe \& Smith, 1996; Margittai et al., 2015). Brañas-Garza et al. (2010) found that social integration and social distance are complementary determinants of altruism. Goeree et al. (2010) and Leider et al. (2009) adopted a different approach to the study of altruism and social distance, collecting information on subjects' social networks. In both instances, the findings emphasise the important role of social distance in explaining differences in altruism, with giving declining with social distance. Goeree et al. (2010) describes this relationship as a simple inverse distance law or so-called $1 / \mathrm{d}$ law of giving. ${ }^{7}$

The existing empirical literature on the Social Discounting Task (SDT) is relatively extensive, with twenty-six studies having been conducted to date (Box 1). These studies can be described as follows:

Social discounting tasks: There are two basic variants of the Social Discounting Task (SDT). In the original, Jones and Rachlin (2006) have subjects choose between a declining amount for themselves and a fixed, equally shared amount for themselves and the relevant person on the list, e.g. row 1 offering $\$ 155$ for you alone (option A) versus $\$ 75$ for you and $\$ 75$ for the first person on the list (option B)(Sharp et al., 2012. Rachlin and Jones (2008b) in turn have subjects face a choice between a declining amount for themselves and a fixed amount for the relevant person on the list, e.g. row 1 offering $\$ 85$ for you alone (option A) versus $\$ 75$ for the first person (\#1) on the list (option B)(Jones \& Rachlin, 2009). ${ }^{8}$

\footnotetext{
${ }^{6}$ Margittai et al. (2015), for example, have subjects play a dictator game with a recipient at each of eight social distances, i.e. 1, 2, 3, 5, 10, 20, 50, 100. Leider et al. (2009) also employs a modified dictator game akin to the Social Discounting Task. The game is called the allocation game and requires decision-makers to "report the maximum price that they would be willing to pay in order for their partner to receive a gain of $\$ 30$ " (Leider et al., 2009: 1827).

${ }^{7}$ Similar results have been obtained using other economics games. Etang, Fielding and Knowles (2011) let subjects play a trust game (TG) and find that trust declines with social distance. Bechler et al. (2015), in their study on social distance, add an ultimatum game (UG) to their dictator game (DG) experiment and report that proposers offered a significantly lower proportion of the initial endowment as the social distance between proposer and responder increased.

${ }^{8}$ There is a small literature that describes social discounting differently and employs a different task to elicit what is called the "index of selfishness" (Ostaszewski \& Osínski, 2011). In this task, subjects make
} 
In the standard tasks, subjects have to envisage a social distance ladder calibrated numerically between 1 (closest person) and 100 (furthest person)(see procedures) and then complete the set of choice tasks for persons at specific social distances, typically 1, 2, 5, 10, 20, 50, 100. In some experiments, though, 'partners' are defined by specific relations rather than a number on a social distance continuum, e.g. 'stranger', 'acquaintance', 'uncle', 'sibling', 'parent' (Boyer, Lienard \& Xu, 2012; Ziegler \& Tunney, 2012), sometimes after rating the perceived social distance to each relation (Strombach et al., 2014/2015).

The two standard tasks, for methodological reasons, have been modified in various ways in experiments. One example of such a study is Yi et al. (2011), who incorporated a delay condition into the task, while He and Jiang (2013) frames the task as gains and losses. Kaplan et al. (2014), using vignettes, framed the SDT in relation to concern and willingness to act in the case of a hypothetical environmental loss, in this case air pollution.

Subjects: The majority of social discounting studies use students as participants. Therefore, these experiments can be classified as conventional laboratory experiments on Harrison and List's (2004) taxonomy. However, some studies recruited field subjects and represent artefactual or framed field experiments (Harrison \& List, 2004). Bradstreet et al. (2012) studied social discounting in pregnant women who smoke, analysing social discounting amongst smokers, non-smokers and quitters. Participants in Boyer et al.'s (2012) experiment included Chinese employees and Kenyan herders, while Sharp et al. (2012) in turn studied $2^{\text {nd }}$ to $12^{\text {th }}$ grade boys. Yi et al. (2011) employed active methamphetamine users as subjects, and Olson et al. (2016) 18-45 year old community members.

Size: The experiments can be described as relatively small, with the number of subjects ranging from 27 (Strombach et al., 2015) to 1,049 (Ito, Saeki \& Green, 2011). Sixty-five percent of studies (17/26) comprised samples of approximately 200 or fewer subjects.

Settings: The vast majority of studies was conducted in developed countries, mainly the United States. Other countries where studies have been conducted include China (Boyer, Lienard \& Xu, 2012; He \& Jiang, 2013; Strombach et al., 2014), Germany (Böckler, Tusche \& Singer, 2016; Strombach et al., 2014/2015/2016), Japan (Ito et al., 2011), Kenya (Boyer et al., 2012) and Poland (Osínski, 2010; Osínski, Karbowski \& Ostaszewski, 2015).

(hypothetical) choices between a smaller monetary reward for themselves only (option A) or a larger reward shared equally with a specified number of persons (option B) (Osínski, Ostaszewski \& Karbowski, 2014). Separate tasks are implemented for people related to the subjects in different ways from a social perspective, e.g. related or unrelated (Osínski et al., 2014) and strangers (unfamiliarity), acquaintances and friends (friendship), and relatives and family (kinship) (Ostaszewski \& Osínski, 2011). 
Experimental tasks: To explore the association of altruism with other preferences or choice sets, the SDT in some experiments has been employed in tandem with other experimental tasks, including Probability (PDT) and Delay Discounting Tasks (DDT) (in Economics better known as risk and time preference elicitation) (Boyer et al., 2012; Rachlin \& Jones, 2008b; Yi et al., 2012; Ziegler \& Tunney, 2012) as well as the Prisoner's Dilemma (PD) (Locey, Safin \& Rachlin, 2013) and Public Goods Game (PGG) (Jones \& Rachlin, 2009). Strombach et al. (2015) implemented the SDT in a neuro-economics experiment, while Kaplan, Reed and McKerchar (2014) investigate the link of social discounting with experimental choices on environmental loss.

Data: In addition to experimentally measuring social discounting and other social preferences, studies at the minimum collect basic socio-demographic information. Behavioural studies, moreover, i.e. investigations of the association of social discounting with behaviour, collect various additional data using questionnaires. Examples including smoking (Bradstreet et al., 2011), culture (Strombach et al., 2014), problematic behaviour in boys (Sharp et al., 2012), and methamphetamine use (Yi et al., 2012). Other studies, notably those investigating the psychology of social discounting, collect data using psychometric instruments. One example is Olson et al. (2016), who employs the Intolerance of Uncertainty Scale (IUS), the Empathy Quotient (EQ60), and the WASI intelligence test, while Böckler et al. (2016) utilise the Prosocialness Scale, Machiavelli Index, and Interpersonal Reactivity Index (IRI). ${ }^{9}$

Key empirical findings from social discounting experiments include the following:

Findings: As expected, participants in these studies indicated that they would be much more generous to those close to them and much less generous to the socially distant. According to Sharp et al. (2011), this form of discounting refers to the fact that most people assign more value to the welfare of close affiliates than they do the welfare of distant affiliates. This empirical result at a theoretical level is consistent with kin-selection theory, because, even at the same social distance, participants were willing to forego significantly more money for the benefit of relatives than for the benefit of non-relatives (Rachlin \& Jones, 2008a).

[Figure 1 about here]

\footnotetext{
${ }^{9}$ Böckler et al. (2016) utilise a battery of game theoretical and other tasks together with a social value orientation (SVO) scale and three other psychological trait scales to decompose key facets of human prosociality. Exploratory (EFA) and confirmatory (CFA) factor analysis is applied to fourteen different measure of human prosociality, of which the social discounting rate represents one and which is a strong and significant component of "altruistically motivated prosocial behaviour".
} 
Similar to time preferences or inter-temporal discounting, the hyperbolic discounting function better fits the data generated from the Social Discounting Task compared to the exponential function (Figure 1) (Jones \& Rachlin, 2006; Locey et al., 2011; Sharp et al., 2012).

Various studies have investigated social discounting from a cross-cultural perspective, showing that social discounting functions are significantly different across individualistic (or Western) as opposed to collectivist (or Asian or African) cultures. Collectivist cultures have been found to be more altruistic than individualistic cultures (Boyer et al., 2012; Ito et al., 2011; Strombach et al., 2014).

Social discounting, as expected, is associated with time, risk and other social preferences. Social distance is correlated positively with rates of cooperation in a one-shot public goods game (Jones \& Rachlin, 2009). The social discounting factor is also correlated with risk attitudes and time preferences, measured using Probability and Delay Discounting Tasks (Jones \& Rachlin, 2009). ${ }^{10}$

Three field experiments have investigated how social discounting relates to (problematic) human behaviour. Bradstreet et al. (2012) found that social discounting is a significant predictor of either smoking or quitting. Sharp et al.'s (2012) main finding is that boys functioning in the clinical range of indices of externalising behavioural problems demonstrated steeper social discounting compared to controls, i.e. that steeper social discounting (in this case less altruism) is correlated with forms of psychopathology in children. Yi et al. (2012), moreover, reported that active methamphetamine users, compared to non-using controls, exhibit higher social discounting, i.e. are less generous.

In Psychology, social discounting experiments in some cases focuses on the behavioural moderators explaining observed differences in altruism, including intolerance of uncertainty and empathy (Olson et al., 2016) and cognitive load (Strombach et al., 2016), which impact social discounting differently in men and women.

[Figure 2 about here]

An important design feature of social discounting experiments that have been investigated experimentally is the use of hypothetical or real incentives. This one study, the one most relevant for the purpose of this paper as it has a similar goal, is the work of Locey et al.

\footnotetext{
${ }^{10}$ According to Psychology's Construal Level Theory (Trope \& Liberman, 2010), social discounting comprises one dimension only of psychological distance or horizon more broadly, together with delay and probability discounting (Kaplan et al., 2014; Yi et al., 2012). In this literature, social distance is defined as a subjective closeness toward a target person, which varies from very close to very distant (Trope \& Liberman, 2003).
} 
(2011) with 40 undergraduate Psychology students. Locey et al. (2011) found that real rewards as opposed to hypothetical rewards made no significant difference in the measurement of cooperation, although the social discounting function for real rewards was slightly higher than for hypothetical rewards (Figure 2), i.e. those receiving real rewards were more altruistic compared to those not paid in real money.

Social discounting tasks may suffer from a number of limitations that are shared with the typical experiment on social preferences, such as experimenter demand effects (Zizzo, 2012). Experiment results, may be subject to "house money" effects (Carlson \& Martinsson, 2013; Clark, 2002; Danková \& Servátka, 2015) insofar as subjects are giving away the experimenter's rather than their own money and therefore are relatively generous. ${ }^{11}$ Nevertheless it is not obvious why these effects should have a differential impact on partners who are near or far in social distance.

\section{Experiment}

In what follows, we outline the characteristics of participants and setting and the experimental procedure and treatment.

Participants and setting: In this study, Rachlin and Jones' (2008b) standard Social Discounting Task (SDT) was replicated twice in two separate sessions. The Session 1 subjects are 45 undergraduate students at the University of the Free State in South Africa. Subjects were recruited using flyers distributed among students attending a lecture for thirdyear Economics students. The subjects in Session 2 are 72 undergraduate students at the same university, recruited from among students attending a second-year Economics lecture.

Ethics: Ethical clearance for the study was obtained from the Faculty of Humanities at the University of the Free State (UFS-HUM-2015-74). Participation was voluntary and written informed consent was obtained from subjects.

\footnotetext{
${ }^{11}$ The structure of the SDT game, however, does not take on the classical endowment-type game (such as a dictator, trust or voluntary contribution mechanism game), where decisions are made regarding the allocation from an endowment to another person or common pool and hence makes the "house money" effect a lesser threat to the methodological soundness of the task. Instead, decisions are made regarding a lesser amount of money for oneself or the same amount of money for someone else. Nevertheless, a between-subject experimental design can be used to answer the question as to whether an endowment effect is present, comparing the treatment in this experiment to an identical Social Discounting Task played after endowing subjects with real earned money equivalent to the amount given to the other person at each social distance (in this case R160) in exchange for performing a basic task. Yet, the amount to be kept may or may not be interpreted as an additional endowment, while the difference between the amount kept or sent may be considered a net endowment. These difficulties render the implementation of such design complex and likely impossible without modifying the structure of the original Social Discounting Task (SDT).
} 
Procedure: Following a pilot of the relevant elicitation procedure with a small group of postgraduate student subjects, a pencil-and-paper instrument including Rachlin and Jones' (2008b) standard Social Discounting Task (SDT) was administered to study participants.

First, the task was explained to subjects using detailed instructions and a practice table (Annexure A1). Subjects then completed a series of seven uniform tables, one for each social distance. In each table, subjects were asked to make choices between an amount of money for themselves versus an amount of money for each of the people on their social distance ladder. (Annexure A2). The basic instruction for each table was as follows:

"Imagine you made a list of the 100 people closest to you in the world ranging from your dearest friend or relative at $\# 1$ to a mere acquaintance at $\# 100$. Now imagine the following choices between an amount of money for you and an amount for the \#1 person on the list. Circle A or B on the right hand side to indicate which you would choose in EACH line."

In each case, the $\# 1$ in the above instruction and in the table and other forms, including the recipient questionnaire, was replaced by $\# 2, \# 5, \# 10, \# 20, \# 50$, \#100, respectively. The task was counter-balanced, with the pages in half of the experimental packages organised in the standard ascending order and in the other half in descending order in terms of the seven social distances (see supplementary material).

Subjects also completed two short questionnaires, providing brief information on the person occupying each social distance [recipient characteristics] (Annexure A4) and, finally, sociodemographic details on themselves [sender characteristics] (Annexure A5).

Treatment: On arrival at the venue, subjects were assigned consecutively to two different rooms. Approximately half of the participants were randomly assigned to the "real money" (payment) group $(n=60)$. This group completed an adapted version of the standard task offering real pay-offs, the difference being the inclusion of specific payment instructions (Annexure A3). The other subjects were assigned to the "hypothetical money" (non-payment) group $(\mathrm{n}=57)$ and instructed to complete the standard non-incentivised task. A key difference in the instructions for the Social Discounting Task was a section that read, "None of your choices will be for actual money, but we ask that you still make choices as if real money were involved" (non-payment group) versus "One of the choices you make will be for real money", with the inclusion of details of the payment procedure - Annexure A3) (payment group) (see supplementary material). 
Payment: Subjects in Session 1 received a show-up fee of R30. Given the relatively low turnout in the first session, the show-up fee in Session 2 was increased to R50. On completion of the experiment, a within-subject random incentive system (RIS) was used to calculate subjects' earnings (Baltussen et al., 2012), by first randomly selecting one of the seven social distances for each subject individually, then selecting one of the specific task's ten rows randomly, and finally playing out the selected choice (A/B) on the selected row (Annexe A3). Where option A was selected, the relevant amount is paid to the subject, whereas where option B was selected, a person at the relevant social distance is nominated by the subject as recipient of the payment and subsequently paid. ${ }^{12}$ Each subject met individually with the experimenter or assistant to implement the randomised payment process and payment was made in private. Subjects on average earned R150 (exclusive of the show-up fee). Payments were cash and made via mobile phone.

\section{Analysis}

According to Olson et al. (2016: 60), the "social discounting paradigm is a powerful means of quantifying altruism in humans". The Social Discounting Task (SDT) measures altruism (or prosocial behaviour more generally) as, the "amount of money a participant [is] willing to forego to give a fixed amount to another person" situated at a specific social distance (Rachlin \& Jones, 2008b). The crossover value is the mean point at which the subject switched from choosing A to choosing B on each table. ${ }^{13}$ For example, if a subject chose the selfish option at R180 for me or R160 for you and switched to the generous option at R160 for me or R160 for you, the crossover point is calculated as R170. If the subject switched between R100 for me or R160 for you and R80 for me or R160 for you, the crossover point is R90. Where option B was selected throughout, the crossover point is assumed to be R190 and where option A was selected throughout the crossover point is assumed to be zero. ${ }^{14}$

\footnotetext{
${ }^{12}$ Payment, in theory, is anonymous, but the sender may disclose their identity to the recipient or the recipient in turn may ask the sender regarding the payment. Subjects were not asked or required to refrain from disclosing their identity to recipients. Where such disclosure is common, reciprocity may represent an important explanation for observed altruism (hypothesis 2 - see below).

${ }^{13}$ Inconsistent preferences remain a limitation with MPL-type elicitation tools such as the Social Discounting Task (SDT). Forty-eight or $41.1 \%$ of subjects switched multiple times from A to B on at least one table, which may be indicative of a lack of understanding or may reflect preference reversals. Sharp et al. (2012), however, report a much higher rate of inconsistent preferences, i.e. $66.5 \%$. To deal with this problem, one could potentially rephrase the task so as to ask subjects to mark the one row where they would choose to switch from A to B, as in the sMPL variant of the multiple price list (MPL) elicitation method (Andersen et al., 2006). In this study, however, the original, standard social discounting task (SDT) protocol was implemented to allow comparability with other social discounting studies, in particular with Locey et al. (2011), who conducted a similar experiment.

${ }^{14}$ One, however, would not expect subjects to select A throughout, because the last option in row 10 is a choice between zero for oneself and R160 for the other person. Altruism should prevail and subjects preferring A over
} 
Based on the literature, two main but opposing hypotheses guide the analysis of the crossing point data. On the one hand, it is hypothesised that subjects completing the incentivised task may be less altruistic than subjects completing the standard task. Generally, due to hypothetical bias (Vlaev, 2012), when faced with the prospect of earning real money (as opposed to giving money to others), subjects are expected to exhibit selfish behaviour and in this case to switch from A to B only in the latter rows of the table, specifically for the more socially distant recipients [hypothesis 1]. On the other hand, it could be hypothesised that subjects, under the condition of real incentives, may be more altruistic insofar as potential recipients, who receive actual money, can identify the donor (Locey \& Rachlin, 2015) (who in turn in an act of reciprocity may potentially share that money with the subject). In other words, receivers may potentially learn from whom they may receive a payment and senders correspondingly may give more. Osínski (2010), in line with this, found that preferences for sharing increases as a function of prospects for reciprocity. Due to the presence of enforced reciprocity (Leider et al., 2009), subjects completing the incentivised task could therefore switch from $\mathrm{A}$ to $\mathrm{B}$ in the early rows, i.e. be more altruistic, especially at closer social distances [hypothesis 2]. ${ }^{15}$

In a similar manner, making payment real might also change the nature of the target individual. The null hypothesis is that treatment has no effect on the type of target, but we do not have a compelling formal or informal theory of how making payments real will change the set of recipients so we leave the alternative hypothesis open.

The analysis comprises six components: first, the subject population is described in terms of their socio-demographic and other characteristics, disaggregating the analysis by treatment arm. As a precursor to the descriptive and multiple regression analysis of the main study outcomes, recipient characteristics are compared across the treatment arms and the seven social distances. A comparative descriptive account of the distribution of crossover values by social distance and treatment arm follows. Subsequently, social discounting functions are fitted individually on each subjects' crossover values with the aid of Reed, Kaplan and Brewer's (2012) Excel solver toolkit, using the following hyperbolic discounting function:

B in row 1-9 should be switching to B in the final row. Yet, envious or spiteful subjects may choose to withhold R160 from another person, especially perhaps those at further social distances. Alternatively, subjects may not have fully understood the task and one could use such response as a manipulation check. In this study, a total of nineteen or $16.2 \%$ of subjects selected A throughout in one or more of the seven tables. If these responses are also considered inconsistent preferences, the total number of subjects exhibiting inconsistent preferences increases to fifty-nine $(50.4 \%)$.

${ }^{15}$ Leider et al. (2009) decompose prosocial behaviour into baseline altruism (toward strangers), directed altruism (toward friends and relatives) and "giving motivated by the prospect of future interaction" (enforced reciprocity). 


$$
v_{i}, j=\frac{A_{i}}{1+k^{\prime} N_{i, j}}
$$

, where $\mathrm{v}_{\mathrm{i}, \mathrm{j}}$ represents the value person $i$ attaches to the welfare of person $j, A_{\mathrm{i}}$ represents the value person $i$ associates with her own welfare, and $N_{i, j}$ is the rank person $i$ assigns to person $j$ among $i$ 's full list of associated people. The constant $k^{\prime}$ measures the steepness of discounting: the greater $k^{\prime}$, the greater the degree of social discounting and the lower the degree of altruism (Sharp et al., 2012: 239). In addition, separate hyperbolic curves are fitted onto the median crossover values of the treatment (payment) and control (non-payment) groups.

Area under the curve (AUC) analysis (Myerson, Green \& Warusawitharana, 2001; Reed, Kaplan \& Brewer, 2012) yields a single a-theoretical discounting parameter independent of functional form and inversely proportional to the rate of discounting, ranging from 0 (complete discounting - less altruism) to 1 (no discounting - greater altruism) (Locey et al., 2011; Osínski, 2010; Yi et al., 2011). An AUC index is constructed for each individual subject, using the Excel software of Reed, Kaplan and Brewer (2012), and then compared between the treatment (payment) and control (non-payment) groups using a two-sample t-test.

In what follows, various regression models are first employed to regress social distance and sender and recipient characteristics on crossover values together with dummy variables for Session, and most importantly, for treatment (payment) status. Sender characteristics include age, gender, household poverty, and previous participation in experiments. Recipient characteristics include age, gender, family relationship ${ }^{16}$, and intergenerational solidarity. ${ }^{17}$ Five different models are estimated: first, an ordered probit model is estimated, treating crossover values as an ordinal outcome. Assuming crossover values to be a continuous outcome, a pooled linear OLS regression model is estimated. Allowing for the panel nature of the data (i.e. subjects being observed multiple times), a linear random (RE) and fixed effects (FE) OLS model is estimated together with a mixed random effects regression model that allows the intercept and coefficient on social distance to vary across subjects.

\footnotetext{
16 "Family" includes partners, parents, siblings and other family, while "non-family" includes friends, neighbours, acquaintances, and strangers (Annexure A4).

${ }^{17}$ To explore the role of social dynamics in explaining differences in inter-personal altruism, a composite index of intergenerational solidarity was constructed using multiple correspondence analysis (MCA). The index includes three components, namely associational, affectual and structural solidarity (Bengtson \& Roberts, 1991). The three components are represented by the following questions: "How often do you communicate with this person?"; "On a ten-point scale, at an emotional and psychological level, how close do you perceive yourself to be to this particular person?"; "How far does this person life from you?" (Annexure A4). The percentage of inertia explained by the first dimension of the intergenerational solidarity construct is $64.6 \%$.
} 
Next, individual estimates of $\mathrm{k}^{\prime}$, the natural logarithm of $\mathrm{k}^{\prime}$, and the AUC index are employed as dependent variables alongside the following independent variables: payment and session dummies, and four sender characteristics, namely age, gender, household poverty, and previous experimental experience. In both cases, regression analyses are conducted for the full sample and restricted sample, which exclude all subjects with inconsistent preferences, i.e. multiple switches or zero crossovers.

\section{Results}

The results of the analysis are presented below.

\subsection{Sender characteristics}

Table 1 shows that the median age of subjects is 22 years. The majority of subjects are African females speaking Sesotho and, as expected given the recruitment strategy, enrolled in the Faculty of Economic and Management Sciences. Furthermore, subjects are relatively well-off in terms of their financial situation, both in respect of their household's poverty status (mostly laying on the $3^{\text {rd }}$ rung of the poverty ladder) and their own personal financial position (two thirds of subjects were not broke). More than a third of subjects had applied for financial aid to the University, with only one in three having been successful. Only three subjects had previously participated in an experiment of a similar nature. When comparing subjects' characteristics across the treatment and control group to assess the extent of balance, only the subject's race and application for financial aid was statistically significant. As many as $91.7 \%$ of subjects in the control group are African, compared to $71.9 \%$ in the treatment group $(\mathrm{p}=0.017)$. A greater proportion of subjects in the control group had applied for financial aid compared to the treatment group $(p=0.006)$. All other variables did not differ significantly by treatment arm, thus suggesting some degree of balance on subject characteristics.

[Table 1 about here]

\subsection{Recipient characteristics}

Because subjects can choose their own recipients and there are a large number of potential social relationship, it is not straightforward to measure the effect of making payment real on the choice of target. Based on the categories offered to the subjects, initially we group recipient types into the following groups: Partner, Parent, Sibling, Other family, Friend, Neighbour/acquaintance, Stranger and Other (see Table 2). We find no significant difference 
in the categories chosen by treatment (chi-squared test, $\mathrm{p}=0.881$ ). Grouping in other ways, such as family versus non-family also showed no significant differences between treatments. The results are summarised in Table 2 where we compare the pattern of recipients based on distance to subject, frequency of contact, age and gender. According to the evidence, the recipients identified by subjects for the most part are not statistically significantly different when compared by treatment $(\mathrm{p}>0.05)$, i.e. the recipients on average are indistinguishable. Only the difference in distance is weakly significant $(\mathrm{p}=0.083)$ : when payment is real subjects are more likely to choose recipients living with them.

[Table 2 about here]

Table 3 however reveals that there as expected are strong, statistically significant differences between recipient characteristics across the seven social distances $(p<0.001)$. Overall, recipients at closer social distances can be described as older female family members knowing the subject for longer than ten years. Closer recipients also daily communicate with subjects insofar as they generally live together. Moreover, recipients perceive their relationships with those recipients at close social distances to be emotionally and psychologically close. The opposite is true for recipients at greater social distance, where emotional and psychological ties are weak.

[Table 3 about here]

\subsubsection{Payment and recipient characteristics}

To examine the effect of paying subjects on the characteristics of recipients we estimate equations of the form:

$$
y=\alpha+\beta_{1} \text { Payment }+\sum_{i=2}^{i=N} \beta_{2 i} S D_{i}+\sum_{i=2}^{i=N} \beta_{3 i} S D_{i} \text { Payment }+X \beta^{\prime}
$$

Where Payment is a dummy variable taking the value 1 if payment is actually made, $\mathrm{SD}_{\mathrm{i}}$ is a dummy for social distance at rank $\mathrm{i}(\mathrm{i}=2,5,10,50$ and 100 - rank 1 is the omitted category) and $X$ is a set of other control variables with $\beta$ ' as the corresponding vector of parameters for $X$. In all the equations the controls are age of the subject, subject's gender, subject's prior experience of experiments and subject household's poverty status. The dependent variables considered correspond to those described in Table 2 above. That is, physical distance to the recipient, psychological distance, solidarity, frequency of communication, age, gender and whether or not the recipient is family or other. For the last two variables we use a probit 
model. For the other dependent variables, though the data is ordinal in some cases we use ordinary least squares (OLS). ${ }^{18}$ Table 4 presents the results of regression analysis of the link between payment and recipient characteristics. Since there are interaction terms to consider when evaluating the impact of treatment, instead of the regression coefficients we present estimates of the marginal effects (i.e. the effect of moving payment from 0 to 1 ) with standard errors estimated using the delta method. As can be seen, for most of the dependent variables there is little impact from making real payments. The exceptions to this pattern are physical and psychological distance. Making payments real makes it more likely that the person ranked $1^{\text {st }}$ is someone living closer to the subject. Meanwhile for lower ranked positions, payment makes it more likely that the chosen recipient is someone living physically further away. ${ }^{19}$ One candidate explanation is that subjects realise that they might have to supply an address if the payment is real, but in fact the frequency of not knowing the subject's address is almost the same in the two treatments $(7.1 \%$ for the hypothetical payment and $11.1 \%$ for the real payment) and omitting this group of recipients does not alter the pattern of results. In the case of psychological distance, payment has a negative and significant impact on the psychological closeness of recipients with lower ranks. That is, not-paying subjects means that they are more likely to state that they are close to lower ranked recipients. Note that for both physical and psychological distance payment does not have a significant impact on the mean distance. Rather it is the gradient that is changed by payment, which sharpens the difference between recipients chosen at the highest and lowest ranks. For the other features of recipients, whether the payment is real or not seems to have little or no impact on the recipient characteristics at any rank. In particular, subjects are not more likely to choose family members for example, when payment is real.

[Table 4 about here]

\subsection{Crossover values}

Figure 3 shows the aggregate distribution of crossover points for subjects in the entire sample, illustrating considerable heterogeneity in the levels of altruism among subjects. Figure 4 illustrates the distribution of crossover values for the control (non-payment) and treatment (payment) groups. A larger proportion of subjects in the control (non-payment) group crossed

\footnotetext{
${ }^{18}$ Using an ordered probit model for instance, does little to change the pattern of results so we stick to the more straightforward OLS specification.

${ }^{19}$ In the physical distance question the last group are people whose addresses are not known to the subject. That does not exactly fit the distance concept. If we omit this group in the estimation, it does not change the pattern of negative coefficients for ranks closer to 1 and positive coefficients for ranks closer to 100 .
} 
over at the lowest crossover values compared to the treatment (payment) group. The opposite is observed at the opposite extreme, where a larger proportion of subjects in the treatment (payment) group crossed over compared to the control (non-payment) group. There is no discernible pattern at intermediate crossover values.

[Figure 3 about here]

[Figure 4 about here]

Table 5 reports the mean and median crossover values calculated across each of the seven social distances, by treatment arm. The mean crossover value for the payment (treatment) group is R113, compared to the non-payment (control) group's mean of R108, a difference that is not statistically significant $(\mathrm{p}=0.242)$. The differences in mean and median crossover values are also not statistically significant across each individual social distance $(p>0.05)$, nor does the median differ on aggregate between treatment arms $(p=0.692)$. Therefore, there is insufficient evidence from this basic descriptive analysis to conclude that subjects in the payment (treatment) group are more or less altruistic than subjects in the non-payment (control) group by a statistically significant margin. Importantly, however, all four sets of figures reflect the strong negative association between expressed altruism and social distance.

[Table 5 about here]

Given the preliminary findings from the descriptive work, it is left to the regression analysis to determine which way the statistical evidence leans regarding the central research question. The ordered probit regression results for the crossover values are reported in column 1 in Table 6 . The coefficients on social distance, as expected, are negative and highly statistically significant. The amount subjects are willing to forego to give someone else R160 declines as social distance increases (as illustrated in Figure 9). This is the case in each of the five regression models. The treatment dummy is statistically significant and positive, i.e. subjects in the treatment (payment) group are relatively more altruistic, which suggests that on aggregate the reciprocity effect may dominate hypothetical bias. Among the sender characteristics, previous experience in laboratory experiments is a strong predictor of altruism. Those with experimental experience are significantly more altruistic. Age also predicts crossover values: older subjects are relatively more altruistic. Gender is only weakly significant, with female subjects being more altruistic than male subjects. Recipients' age also matters, with subjects being more altruistic toward older recipients. 
[Figure 9 about here]

Intergenerational solidarity has a positive and statistically significant sign. Altruism increases as intergenerational solidarity improves. As for the role of kinship and kin selection, which is highly correlated with social distance (Figure 10), the family dummy variable only turns highly statistically significant when the social distance variable is dropped from the regression models. (Results not reported here.) Figure 10 reports the mean crossover values for different social relations. As expected, subjects are more altruistic toward those close to them, especially their parents, and least altruistic toward mere acquaintances and strangers.

[Figure 5 about here]

[Table 6 about here]

Next, the regression analysis is replicated using linear OLS. The results, as expected, do not change. With the exception of two coefficients, those for treatment (payment) and subject's gender, both now not statistically significant; the random effects (RE) regression results mirror the findings from the pooled regression models. Furthermore, intergenerational solidarity now is only weakly significant, while the coefficient on social distance "2" turns highly significant. The random effects (RE) regression model, as expected, better explains variation in crossover values within subjects $\left(R^{2} 0.363\right)$ than between subjects $\left(R^{2} 0.110\right)$. The fixed effects (FE) regression model confirms the random effects (RE) results for social distance, recipient's age, and intergenerational solidarity, and so too the mixed random effects (RE) model, the only exception being recipient's gender, which now is positive and weakly statistically significant. In regards to sender characteristics, the mixed random effects (RE) model mirrors the standard linear random effects (RE) regression model, with sender's age and previous experimental experience being positive and statistically significant, as was the case in each of the regression models.

There are seven differences between the regression results for the restricted and full samples. Firstly, the payment dummy is not statistically significant in any of the five regression models. Secondly, the recipient's age turns insignificant in the latter three regression models, while in the third instance the recipient's gender never is statistically significant. Fifth, intergenerational solidarity now is only significant in three regression models. Sixth, sender's age and gender vary in terms of significance and generally is less significant. A final but major difference is that household poverty now is positive and statistically significant across the 
five regression models. Otherwise, previous experimental experience remains a strong predictor of crossover values over the various estimators.

\subsection{Social discounting rate}

Figure 5 reports the distribution of $\ln \left(\mathrm{k}^{\prime}\right)$ in the sample. The mean discount rate for subjects in the control (non-payment) arm is 0.077 compared to 0.038 in the treatment (payment) arm. The result is weakly significant in statistical terms $(p=0.091)$. The difference is more pronounced when restricting the analysis to the smaller sample of subjects with consistent preferences: control - non-payment 0.099 versus treatment - payment $0.023(\mathrm{p}=0.069)$. Figure 6 illustrates the hyperbolic social discounting functions for each treatment arm. Paid subjects are more altruistic than non-incentivised subjects, particularly at greater social distances. There is some descriptive evidence, therefore, similar to Locey et al. (2011), in support of enforced reciprocity [hypothesis 2].

[Figure 6 about here]

The aggregate figures are 0.058 (full sample) and 0.063 (restricted sample), which compares favourably to those reported by Jones and Rachlin (2006/09), Locey et al. (2011), Osínski (2010), Rachlin and Jones (2008b), and Sharp et al. (2012). However, the estimates fall below those reported by Strombach et al. (2014), but exceed those reported by Osínski, Karbowski and Ostaszewski (2015).

[Figure 7 about here]

In the next part of the analysis, summarized in Table 7, the treatment and session dummies and sender characteristics are regressed on individual discount rates $\left(\mathrm{k}^{\prime}\right)$, using Tobit and OLS regression models, respectively. First, the results are presented for the restricted sample. Two regressors are statistically significant in the Tobit regression model. Discounting rates (altruism) are significantly lower (greater) in those with previous experience in laboratory experiments and so too in the treatment (payment) arm of the study. The same results are obtained using the full sample, the only exception being that subject's age now is negative and statistically significant. In other words, older subjects are more altruistic. Only in the OLS model with $\ln \left(\mathrm{k}^{\prime}\right)$ for the restricted sample is previous experimental experience also statistically significant. However, this result is largely inconclusive as the OLS regression models do not pass the criterion for overall fit.

[Table 7 about here] 


\subsection{Analysis under the curve}

The distribution of the AUC index across study subjects is reported in Figure 7. The mean AUC index for the control (non-payment) group (0.462) is slightly greater than the treatment (payment) group's AUC (0.448). Contrary to the above results on $\mathrm{k}^{\prime}$, subjects in the payment (treatment) are less altruistic than their counterparts in the non-payment (control) group, as would be the case under hypothetical bias. The corresponding figures for the restricted sample, which is slightly smaller than the estimates for the full sample, are 0.439 (control); 0.433 (treatment); 0.436 (total). There however are no statistically significant differences between the payment and non-payment groups, be it for the full or restricted sample.

Student subjects in this study $(\mathrm{AUC}=0.455)$ in terms of altruism are more or less on par with student subjects in Poland (AUC 0.4 - 0.8) (Osínski, 2010) but considerably less altruistic than students in the US (AUC 0.61 - 0.69) (Locey et al., 2011), yet substantially more altruistic than students in another, earlier US experiment (AUC $0.256 / 0.369$ ) (Jones \& Rachlin, 2009).

[Figure 9 about here]

Figure 10 illustrates the (expected) negative relationship between the two measures of altruism, i.e. the lower $\mathrm{k}^{\prime}$ the higher the AUC index. The respective correlation coefficients are -0.485 (full sample) and -0.473 (restricted sample); both statistically significant.

[Figure 10 about here]

The AUC regression results are presented in Table 8. Both OLS regression models perform adequately in terms of overall fit $(\mathrm{p}<0.01)$. Only two independent variables are statistically significant, namely previous experimental experience (positive) (restricted and full samples) and subject's age (positive) (full sample only). The evidence, with the exception of the payment dummy, corroborates the results from the Tobit model as applied to the full sample.

[Table 8 about here]

\section{Conclusion}

This study conducts an SDT task with South African students and finds five key features in the result. First, the study presents some - albeit relatively weak - evidence that paying out the Social Discounting Task (SDT) matters, as has previously been reported for American 
students by Locey et al. (2011). In particular the evidence suggests that paying leads to a higher cross-over point compared to the treatment where payments are hypothetical.

Secondly, we find evidence that making payments real changes the set of target recipients. In particular it has an effect on physical and psychological distance to recipients although it appears to have no systematic effect on age, gender, frequency of communication, years known and sense of solidarity. The effect depends on rank, and means that the gradient of distance is higher when payment is made - more highly ranked individuals are closer physically and psychologically when payment is real and lower ranked individuals are further away.

Third, subjects on aggregate exhibit an inverse relationship between social distance and altruism in accordance with the 1/d law of giving (Goeree et al., 2010), where more (less) is given to closer (distant) relations. This key finding provides support for the kin selection theory, that greater altruism toward close relatives occurs in order to ensure the continuation of shared genes (Jones \& Rachlin, 2008b).

Further support for this claim on kin selection theory lies in the importance in the analysis of family relations and inter-generational solidarity as predictor of inter-personal altruism. According to this fourth finding, the nature of the specific relationship between sender and recipient is critical. Subjects exhibiting greater intergenerational solidarity with recipients are more altruistic as are subjects related by blood or close social ties.

Finally, although we do not have an exact comparator group, there is no evidence that preferences for altruistic acts in this student population are substantially different from student populations from so-called WEIRD countries.

The study has a number of limitations that are shared with the typical experiment on social preferences, such as the possibility of experimenter demand effects (Zizzo, 2012) and the difficulty of generalising from a group of subjects from one Faculty at a single university in but one country. Nevertheless it provides evidence that the social distance task can be used successfully in settings outside Western industrialised nations. However, it suggests that having hypothetical payments may have a subtle influence on the choice of target recipients and also on the degree of expressed altruism. 


\section{References}

Andersen, S., Harrison, G.W., Lau, M.I. \& Rutström, E.E. (2006) Elicitation using multiple price list formats. Experimental Economics, 9: 383-405.

Baltussen, G., Post, G.T., Van den Assem, M.J. \& Wakker, P.P. (2012) Random incentive systems in a dynamic choice experiment. Experimental Economics, 15: 418-443.

Bechler, C., Green, L. \& Myerson, J. (2015) Proportion offered in the Dictator and Ultimatum Games decreases with amount and social distance. Behavioural Processes, 115: 149-155.

Bengston, V.L. \& Roberts, R.E.L. (1991) Intergenerational Solidarity in Aging Families: An Example of Formal Theory Construction. Journal of Marriage and the Family, 53: 856-870.

Böckler, A., Tusche, A. \& Singer, T. (2016) The Structure of Human Prosociality: Differentiating Altruistically Motivated, Norm Motivated, Strategically Motivated, and Self-Reported Prosocial Behavior. Social Psychological and Personality Science, (in press).

Bohnet, I. \& Frey, B.S. (1999) Social Distance and Other-Regarding Behavior in Dictator Games: A Comment. American Economic Review, 89(1): 335-339.

Boyer, P., Lienard, P. \& Xu, J. (2012) Cultural Differences in investing in others and in the Future: Why Measuring Trust is not Enough. PLoS ONE, 7(7): e40750.

Bradstreet, M. P., Higgins, S.T., Heil, S.H., Adger, G.J.B., Kelly, J.M.S., Lynch, M.E. \& Trayah, M.C. (2012) Social Discounting and Cigarette Smoking During Pregnancy. Journal of Behavioral Decision-Making, 25: 502-511.

Brañas-Garza, P., Cobo-Reyes, R., Espinosa, M.P., Jiménez, N., Kovááík, J. \& Ponti, G. (2010) Altruism and social integration. Games and Economic Behavior, 69: 249-257.

Carlsson, F., He, H. \& Martinsson, P. (2013) Easy come, easy go: the role of windfall money in lab and field experiments. Experimental Economics, 16: 190-207.

Charness, G. \& Gneezy, U. (2008) What's in a name? Anonymity and social distance in dictator and ultimatum games. Journal of Economic Behavior \& Organization, 68: 29-35. 
Clark, J. (2002) House Money Effects in Public Goods Experiments. Experimental Economics, 5: 223-231.

Danková, K. \& Servátka, M. (2015) The house money effect and negative reciprocity. Journal of Economic Psychology, 48: 60-71.

Etang, A., Fielding, D. \& Knowles, S. (2011) Does trust extend beyond the village? Experimental trust and social distance in Cameroon. Experimental Economics, 14: 1535.

Goeree, J.K., McConnell, M.A., Mitchell, T., Tromp, T. \& Yariv, L. (2010) The 1/d Law of Giving. American Economic Review: Microeconomics, 2(1): 183-203.

Harrison, G.W. \& List, J.A. (2004) Field Experiments. Journal of Economic Literature, 42(4): 1013-1059.

He, G. \& Jiang, D. (2013) The effect of task frames and altruism on social discounting. Acta Psychologica Sinica, 45(10): 1131-1146.

Henrich, J., Heine, S.J. \& Norenzayan, A. (2010) The weirdest people in the world? Behavioural and Brain Sciences, 33: 61-135.

Hertwig, R. \& Ortmann, A. (2001) Experimental practices in economics: A methodological challenge for psychologists? Behavioral and Brain Sciences, 24: 383-451.

Hoffman, E., McCabe, K. \& Smith, V.L. (1996) Social Distance and Other-Regarding Behavior in Dictator Games. American Economic Review, 86(3): 653-660.

Ito, M., Saeki, D. \& Green, L. (2011) Sharing, Discounting, and Selfishness: A JapaneseAmerican Comparison. Psychological Record, 60: 59-76.

Jones, B. \& Rachlin, H. (2006) Social Discounting. Psychological Science, 17(4): 283-286.

Jones, B. \& Rachlin, H. (2009) Delay, Probability, and Social Discounting in a Public Goods Game. Journal of the Experimental Analysis of Behaviour, 91: 61-73.

Kaplan, B.A., Reed, D.D. \& McKerchar, T.L. (2014) Using a Visual Analogue Scale to Assess Delay, Social, and Probability Discounting of an Environmental Loss. Psychological Record, 64: 261-269. 
Leider, S., Möbius, M.M., Rosenblat, T. \& Do, Q. (2009) Directed altruism and enforced reciprocity in social networks. Quarterly Journal of Economics, 124(4): 1815-1851.

Liu, P., Safin, V., Yang, B. \& Luhmann, C.C. (2015) Direct and Indirect Influence of Altruistic Behavior in a Social Network. PLoS ONE, 10(10): e0140357.

Locey, M.L, Jones, B. \& Rachlin, H. (2011) Real and hypothetical rewards in self-control and social discounting. Judgment and Decision Making, 6(6): 552-564.

Locey, M.L., Safin, V. \& Rachlin, H. (2013) Social Discounting and the Prisoner's Dilemma Game. Journal for Experimental Analysis of Behaviour, 99(1): 85-97.

Locey, M.L. \& Rachlin, H. (2015) Altruism and anonymity: A behavioral analysis. Behavioural Processes, 118: 71-75.

Luhmann, C.C. \& Pak, S. S. (2013) Won't You Think of the Children?: Traits Predicting Intergenerational Preferences. In M. Knauff, M. Pauen, N. Sebanz, \& I. Wachsmuth (Eds.), Proceedings of the 35th Annual Conference of the Cognitive Science Society (pp. 2949-2954). Austin, TX: Cognitive Science Society.

Margittai, Z., Strombach, T., Van Wingerden, M., Joëls, M., Schwabe, L. \& Kalenscher, T. (2015) A friend in need: Time-dependent effects of stress on social discounting in men. Hormones \& Behavior, 73: 75-82.

Myerson, J., Green, L. \& Warusawitharana, M. (2001) Area Under the Curve as a Measure of Discounting. Journal of the Experimental Analysis of Behavior, 76: 235-243.

Olson, E.A., Rosso, I.M., Demers, L.A., Divatia, S. \& Killgore, W.D.S. (2016) Sex Differences in Psychological Factors Associated with Social Discounting. Journal of Behavioral Decision Making, 29: 60-66.

Osiński, J.T. (2009) Kin altruism, reciprocal altruism and social discounting. Personality and Individual Differences, 47: 374-378.

Osiński, J.T. (2010) Social Discounting: The effect of outcome uncertainty. Behavioural Processes, 85: 24-27.

Osiński, J.T., Karbowski, A. \& Ostaszewski, P. (2015) Social Discounting: Choice between rewards for other people. Behavioural Processes, 115: 61-63. 
Osínski, J.T., Ostaszewski, P. \& Karbowski, A. (2014) Social discounting rate is negatively correlated with fluid intelligence. Personality and Individual Differences, 59: 44-49.

Ostaszewski, P. \& Osínski, J.T. (2011) Social Discounting of Monetary Rewards: The Effects of Amount and Social Relationship. European Psychologist, 16(3): 220-226.

Rachlin, H. (2016) Social Cooperation and Self-Control. Managerial and Decision Economics, 37: 249-260.

Rachlin, H. \& Jones, B.A. (2008a) Altruism among relatives and non-relatives. Behavioural Processes, 79: 120-123.

Rachlin, H. \& Jones, B.A. (2008b) Social Discounting and Delay Discounting. Journal of Behavioral Decision Making, 21: 29-43.

Rachlin, H. \& Locey, M. (2011) A behavioural analysis of altruism. Behavioural Processes, 87: $25-33$.

Reed, D.D., Kaplan, B.A. \& Brewer, A.T. (2012) A tutorial on the use of Excel 2010 and Excel for Mac 2011 for conducting delay-discounting analyses. Journal of Applied Behavior Analysis, 45: 375-386.

Safin, V., Arfer, K.B. \& Rachlin, H. (2015) Reciprocation and altruism in social cooperation. Behavioural Processes, 116: 12-16.

Sharp, C. (2012) The Use of Neuroeconomic Games to Examine Social Decision Making in Child and Adolescent Externalizing Disorders. Current Directions in Psychological Science, 21(3): 183-188.

Sharp, C., Barr, G., Ross, D., Bhimani, R., Ha, C. \& Vuchinich, R. (2012) Social Discounting and Externalizing Behavior Problems in Boys. Journal of Behavioral DecisionMaking, 25: 239-247.

Strombach, T., Jin, J., Weber, B., Kenning, P., Shen, Q., Ma, Q. \& Kalenscher, T. (2014) Charity Begins at Home: Cultural Differences in Social Discounting and Generosity. Journal of Behavioral Decision Making, 27(3): 235-245.

Strombach, T., Weber, B., Hangebrauk, Z., Kenning, P., Karipidis, I.I., Tobler, P.N. \& Kalenscher, T. (2015) Social discounting involves modulation of neural value signals by temporoparietal junction. PNAS, 112(5): 1619-1624. 
Strombach, T., Margittai, Z., Gorczyca, B. \& Kalenscher, T. (2016) Gender-Specific Effects of Cognitive Load on Social Discounting. PLoS ONE, 11(10): e0165289.

Trope, Y. \& Liberman, N. (2003) Temporal construal. Psychological Review, 110: 403-420.

Trope, Y. \& Liberman, N. (2010) Construal-Level Theory of Psychological Distance. Psychological Review, 117(2): 440-463.

Vlaev, I. (2012) How different are real and hypothetical decisions? Overestimation, contrast and assimilation in social interaction. Journal of Economic Psychology, 33: 963-972.

Yi, R., Carter, A.E. \& Landes, R.D. (2012) Restricted psychological horizon in active methamphetamine users: future, past, probability and social discounting. Behavioural Pharmacology, 23: 358-366.

Yi, R., Charlton, S., Porter, C., Carter, A.E. \& Bickel, W.K. (2011) Future altruism: Social discounting and delayed rewards. Behavioural Processes, 86: 160-163.

Yi, R., Pickover, A., Stuppy-Sullivan, A.M., Baker, S., Landes, R.D. (2016) Impact of episodic thinking on altruism. Journal of Experimental Social Psychology, 65:74-81

Ziegler, F.V. \& Tunney, R.J. (2012) Decisions for Others Become Less Impulsive the Further Away They Are on the Family Tree. PlosONE, 7(11): e49479.

Zizzo, D.J. (2010) Experimenter demand effects in economic experiments. Experimental Economics, 13:75-98. 
Figure 1: Exponential and hyperbolic social discounting functions

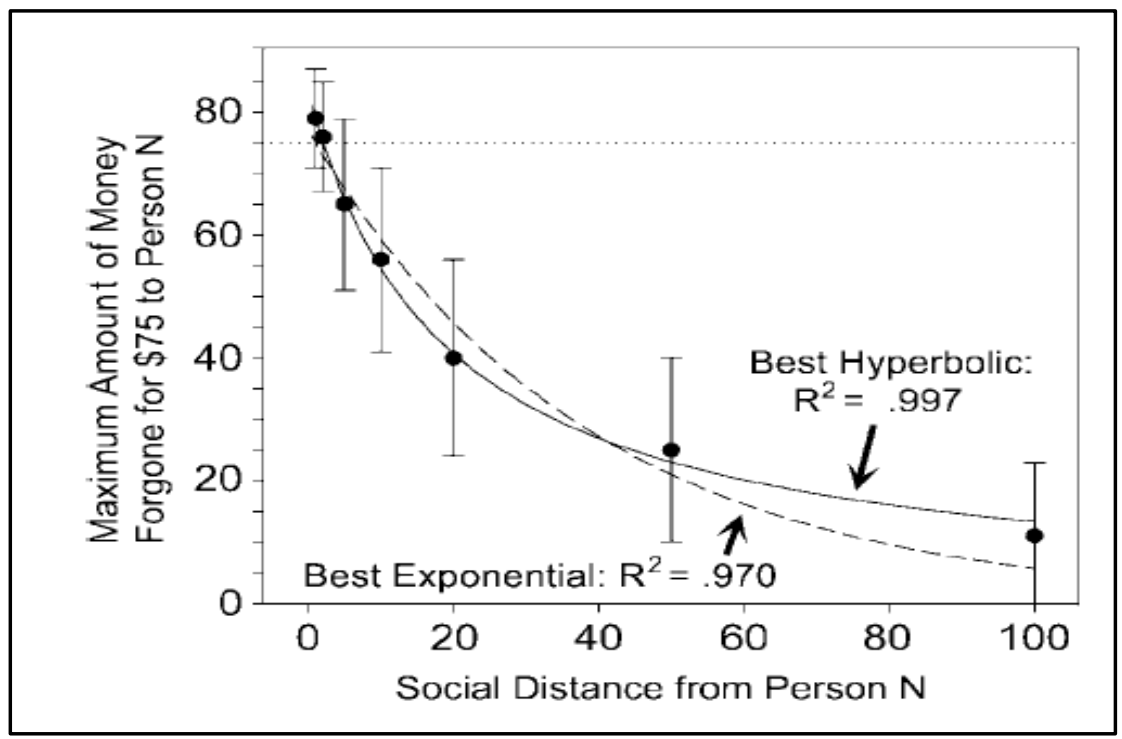

Source: Jones \& Rachlin (2006:285) 
Figure 2: Mean crossover points, for hypothetical and real rewards

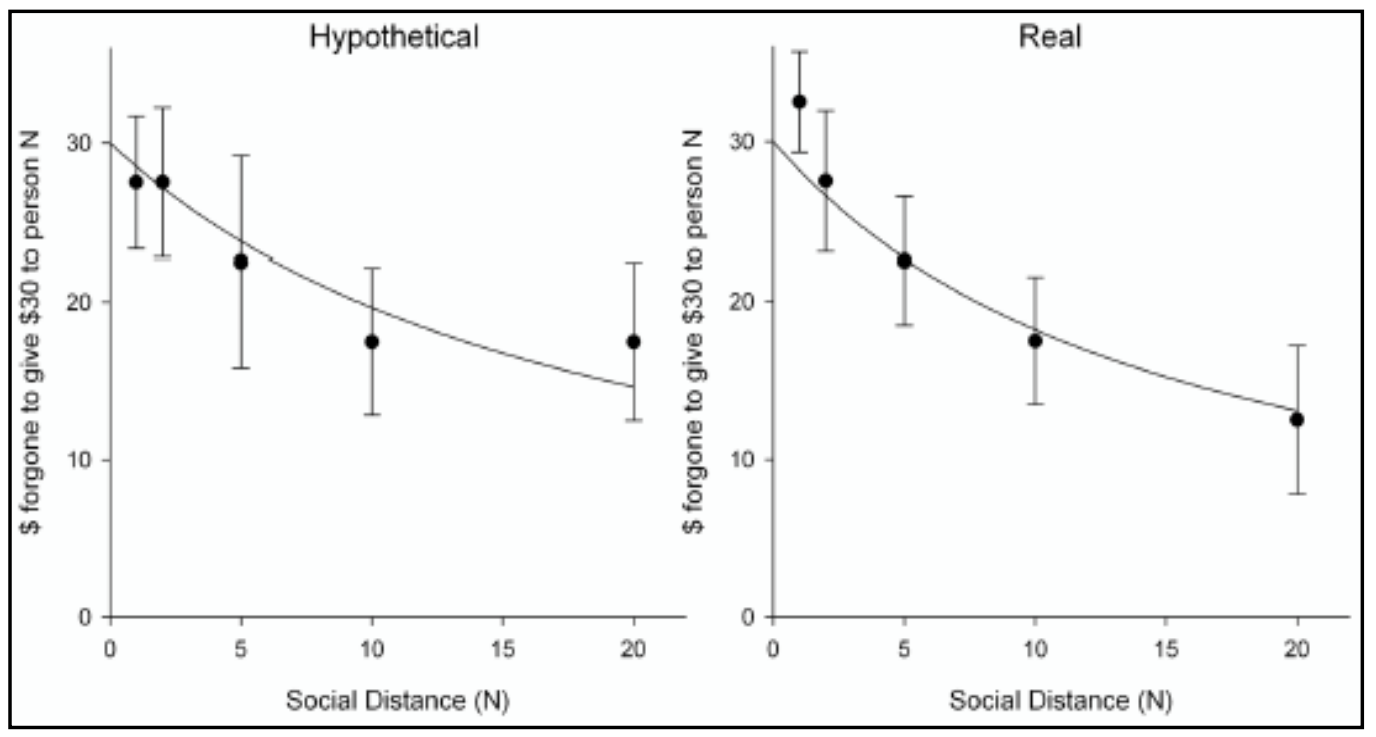

Source: Locey et al. (2011:21) 
Table 1: Subjects - descriptive characteristic, by treatment arm

\begin{tabular}{|c|c|c|c|c|}
\hline & Payment & Non-Payment & Total & p-value \\
\hline \multicolumn{5}{|l|}{ Age (years) } \\
\hline Mean & 22.3 & 22.7 & 22.5 & 0.186 \\
\hline Median [IQR] & $22[24-21]$ & $22[23.5-21]$ & $22[24-21]$ & 0.885 \\
\hline Female (\%) & 54.4 & 63.3 & 59.0 & 0.325 \\
\hline \multicolumn{5}{|l|}{ Population Group } \\
\hline African & 71.9 & 91.7 & 82.1 & 0.017 \\
\hline Coloured & 3.5 & 3.3 & 3.4 & \\
\hline Asian & 10.5 & - & 5.1 & \\
\hline White & 14.0 & 5.0 & 9.4 & \\
\hline Total & 100.0 & 100.0 & 100.0 & \\
\hline \multicolumn{5}{|l|}{ Language } \\
\hline Sotho & 38.6 & 40.0 & 39.3 & 0.935 \\
\hline Afrikaans & 8.8 & 8.3 & 8.6 & \\
\hline Venda & 8.8 & 6.7 & 7.7 & \\
\hline Xhosa & 8.8 & 11.7 & 10.3 & \\
\hline Sepedi & 1.8 & 1.7 & 1.7 & \\
\hline Tswana & 13.3 & 8.8 & 11.1 & \\
\hline English & 15.8 & 6.7 & 11.1 & \\
\hline Tsonga & 1.8 & 3.3 & 2.6 & \\
\hline Zulu & 3.5 & 5.0 & 4.3 & \\
\hline Other & 3.5 & 3.3 & 3.4 & \\
\hline Total & 100.0 & 100.0 & 100.0 & \\
\hline \multicolumn{5}{|l|}{ Faculty } \\
\hline Economic and Management & 82.5 & 68.3 & 75.2 & 0.443 \\
\hline Natural and Agricultural & 8.8 & 18.3 & 13.7 & \\
\hline Health & 3.5 & 5.0 & 4.3 & \\
\hline Education & - & 1.7 & 0.9 & \\
\hline Law & - & 1.7 & 0.9 & \\
\hline Humanities & 5.1 & 5.0 & 5.1 & \\
\hline Total & 100.0 & 100.0 & 100.0 & \\
\hline \multicolumn{5}{|l|}{ Household Poverty } \\
\hline 1 (poorest) & - & 3.3 & 1.7 & 0.629 \\
\hline 2 & 13.3 & 12.3 & 12.8 & \\
\hline 3 & 52.6 & 55.0 & 53.9 & \\
\hline 4 & 31.6 & 26.7 & 29.1 & \\
\hline 5 & 3.5 & 1.7 & 2.6 & \\
\hline 6 (richest) & - & - & - & \\
\hline Total & 100.0 & 100.0 & 100.0 & \\
\hline \multicolumn{5}{|l|}{ Financial Situation } \\
\hline Very Broke & 8.8 & 11.7 & 10.3 & 0.426 \\
\hline Broke & 33.3 & 31.7 & 32.5 & \\
\hline Neither & 26.3 & 36.7 & 31.6 & \\
\hline In good shape & 31.6 & 20.0 & 25.6 & \\
\hline In very good shape & - & - & - & \\
\hline Total & 100.0 & 100.0 & 100.0 & \\
\hline Applied for financial aid (yes) & 21.1 & 45.0 & 33.3 & 0.006 \\
\hline Received financial aid (yes) & 10.5 & 11.7 & 11.1 & 0.844 \\
\hline Previous experimental experience (yes) & 1.8 & 3.3 & 2.6 & 0.531 \\
\hline Sample (n) & 60 & 57 & 117 & \\
\hline
\end{tabular}


Table 2: Recipients - descriptive characteristics $(n=819)$, by treatment arm

\begin{tabular}{|c|c|c|c|c|}
\hline & Payment & Non-payment & Total & p-value \\
\hline \multicolumn{5}{|l|}{ Age (years) } \\
\hline Mean & 31.8 & 32.7 & 32.2 & 0.793 \\
\hline Median [IQR] & $26[41-21]$ & $26[44-21]$ & $26[42-21]$ & 0.769 \\
\hline Female $(\%)$ & 77.2 & 71.7 & 74.4 & 0.494 \\
\hline \multicolumn{5}{|l|}{ Relation } \\
\hline Partner & 8.8 & 6.7 & 7.7 & 0.881 \\
\hline Parent & 68.4 & 70.0 & 69.2 & \\
\hline Sibling & 12.3 & 8.3 & 10.3 & \\
\hline Other family & 5.3 & 6.7 & 6.0 & \\
\hline Friend & 5.3 & 6.7 & 6.0 & \\
\hline Neighbour/acquaintance & - & 1.7 & 0.9 & \\
\hline Stranger & - & - & - & \\
\hline Other & - & - & - & \\
\hline Total & 100.0 & 100.0 & 100.0 & \\
\hline \multicolumn{5}{|l|}{ Relation } \\
\hline Family & 55.9 & 58.1 & 57.0 & 0.524 \\
\hline Non-family & 44.1 & 41.9 & 43.0 & \\
\hline Total & 100.0 & 100.0 & 100.0 & \\
\hline \multicolumn{5}{|l|}{ How long known } \\
\hline$<1$ year & 1.8 & 3.3 & 2.6 & 0.466 \\
\hline 1-2 years & 1.8 & 1.7 & 1.7 & \\
\hline $2-3$ years & 3.5 & 6.7 & 5.1 & \\
\hline $3-5$ years & - & 5.0 & 2.6 & \\
\hline $5-10$ years & 7.0 & 3.3 & 5.1 & \\
\hline$>10$ years & 86.0 & 80.0 & 82.9 & \\
\hline Total & 100.0 & 100.0 & 100.0 & \\
\hline \multicolumn{5}{|l|}{ Communication } \\
\hline Daily & 57.9 & 45.0 & 51.3 & 0.387 \\
\hline A few times a week & 26.3 & 38.3 & 32.5 & \\
\hline Once a week & 3.5 & 5.0 & 4.3 & \\
\hline A few times a month & 5.3 & 5.0 & 5.1 & \\
\hline Once a month & - & 3.3 & 1.7 & \\
\hline A few times a year & 5.3 & 1.7 & 3.4 & \\
\hline Less frequently & 1.8 & - & 0.9 & \\
\hline No contact & - & 1.7 & 0.9 & \\
\hline Total & 100.0 & 100.0 & 100.0 & \\
\hline \multicolumn{5}{|l|}{ Distance } \\
\hline We live together & 56.1 & 31.7 & 43.6 & 0.083 \\
\hline Within walking distance & 10.5 & 10.0 & 10.3 & \\
\hline Same town/village/city & 3.5 & 8.3 & 6.0 & \\
\hline Another town/village/city & 19.3 & 35.0 & 27.4 & \\
\hline Another country & 10.5 & 15.0 & 12.8 & \\
\hline Do not know where person lives & - & - & - & \\
\hline Total & 100.0 & 100.0 & 100.0 & \\
\hline \multicolumn{5}{|l|}{ Psychological and emotional distance } \\
\hline Mean & 6.5 & 6.2 & 6.3 & 0.111 \\
\hline Median [IQR] & $7[9-4]$ & $6[9-4]$ & $7[9-4]$ & 0.365 \\
\hline
\end{tabular}


Table 3: Recipients - descriptive characteristics, by social distance

\begin{tabular}{|c|c|c|c|c|c|c|c|c|c|}
\hline & 1 & 2 & 5 & 10 & 20 & 50 & 100 & Total & p-value \\
\hline \multicolumn{10}{|l|}{ Age (years) } \\
\hline Mean & 41.1 & 35.5 & 28.5 & 33.0 & 28.5 & 29.7 & 29.4 & 32.2 & $<0.001$ \\
\hline Median [IQR] & $47[52-26]$ & $30[50-23]$ & $23[31-19]$ & $25[40-22]$ & $24[33-21]$ & $25[33-21]$ & $24[30-21]$ & $26[42-21]$ & \\
\hline Age differential (mean) & 18.6 & 13.0 & 6.0 & 10.6 & 6.0 & 7.2 & 6.9 & 9.8 & $<0.001$ \\
\hline & & & & & & & & & \\
\hline Female (\%) & 74.4 & 58.9 & 48.7 & 56.4 & 51.3 & 51.3 & 42.7 & 54.8 & $<0.001$ \\
\hline \multicolumn{10}{|l|}{ Relation } \\
\hline Partner & 7.7 & 14.5 & 14.5 & 8.6 & 5.1 & 2.6 & 0.9 & 7.7 & \multirow[t]{9}{*}{$<0.001$} \\
\hline Parent & 69.2 & 30.8 & 6.8 & 4.3 & 0.9 & 0.9 & 1.7 & 16.4 & \\
\hline Sibling & 10.3 & 35.0 & 29.1 & 6.0 & 3.4 & 4.3 & 0.9 & 12.7 & \\
\hline Other family & 6.0 & 12.8 & 30.8 & 42.7 & 35.9 & 23.1 & 6.0 & 22.5 & \\
\hline Friend & 6.0 & 5.1 & 15.4 & 31.6 & 33.3 & 13.7 & 4.3 & 15.6 & \\
\hline Neighbour/acquaintance & 0.9 & - & 2.6 & 5.1 & 20.5 & 47.0 & 24.8 & 14.4 & \\
\hline Stranger & - & 1.7 & 0.9 & 0.9 & 0.9 & 7.7 & 60.7 & 10.4 & \\
\hline Other & - & - & - & 0.9 & - & 0.9 & 0.9 & 0.4 & \\
\hline Total & 100.0 & 100.0 & 100.0 & 100.0 & 100.0 & 100.0 & 100.0 & 100.0 & \\
\hline \multirow{2}{*}{\multicolumn{10}{|c|}{ Relation }} \\
\hline & & & & & & & & & \\
\hline Family & 92.3 & 89.7 & 76.9 & 57.3 & 43.6 & 29.9 & 9.4 & 57.0 & \multirow[t]{3}{*}{$<0.001$} \\
\hline Non-family & 7.7 & 10.3 & 23.1 & 42.7 & 56.4 & 70.1 & 90.6 & 43.0 & \\
\hline Total & 100.0 & 100.0 & 100.0 & 100.0 & 100.0 & 100.0 & 100.0 & 100.0 & \\
\hline \multicolumn{10}{|l|}{ How long known } \\
\hline$<1$ year & 2.3 & 2.6 & 1.7 & 4.3 & 5.1 & 28.2 & 65.8 & 15.8 & \multirow[t]{7}{*}{$<0.001$} \\
\hline $1-2$ years & 1.7 & 3.4 & 7.7 & 6.8 & 15.4 & 15.4 & 9.4 & 8.6 & \\
\hline $2-3$ years & 5.1 & 6.8 & 7.7 & 5.1 & 10.3 & 14.5 & 6.0 & 7.9 & \\
\hline $3-5$ years & 2.6 & 8.6 & 10.3 & 14.5 & 14.5 & 6.8 & 3.4 & 8.7 & \\
\hline $5-10$ years & 5.1 & 3.4 & 9.4 & 17.0 & 19.7 & 10.3 & 2.6 & 9.7 & \\
\hline$>10$ years & 82.9 & 75.2 & 63.3 & 52.1 & 35.0 & 24.8 & 12.8 & 49.4 & \\
\hline Total & 100.0 & 100.0 & 100.0 & 100.0 & 100.0 & 100.0 & 100.0 & 100.0 & \\
\hline Sample (n) & 117 & 117 & 117 & 117 & 117 & 117 & 117 & 819 & \\
\hline
\end{tabular}

Note: Totals may not add up to $100 \%$ due to rounding. 
Table 3: Recipients - descriptive characteristics, by social distance (continued)

\begin{tabular}{|c|c|c|c|c|c|c|c|c|c|}
\hline & 1 & 2 & 5 & 10 & 20 & 50 & 100 & Total & p-value \\
\hline \multicolumn{10}{|l|}{ Communication } \\
\hline Daily & 51.3 & 41.0 & 25.6 & 11.1 & 12.8 & 12.0 & 3.4 & 22.5 & \multirow[t]{9}{*}{$<0.001$} \\
\hline A few times a week & 32.5 & 33.3 & 34.2 & 24.8 & 18.0 & 15.4 & 6.0 & 23.4 & \\
\hline Once a week & 4.3 & 5.1 & 6.8 & 10.3 & 11.1 & 5.1 & 5.1 & 6.8 & \\
\hline A few times a month & 5.1 & 12.8 & 14.5 & 25.6 & 18.8 & 13.7 & 6.8 & 13.9 & \\
\hline Once a month & 1.7 & - & 6.8 & 7.7 & 11.1 & 9.4 & 1.7 & 5.4 & \\
\hline A few times a year & 3.4 & 6.0 & 7.7 & 15.4 & 17.1 & 20.5 & 14.5 & 12.1 & \\
\hline Less frequently & 0.9 & 0.9 & 1.7 & 1.7 & 8.6 & 13.7 & 21.4 & 7.0 & \\
\hline No contact & 0.9 & 0.9 & 2.6 & 3.4 & 2.6 & 10.3 & 41.0 & 9.0 & \\
\hline Total & 100.0 & 100.0 & 100.0 & 100.0 & 100.0 & 100.0 & 100.0 & 100.0 & \\
\hline \multicolumn{10}{|l|}{ Distance } \\
\hline We live together & 43.6 & 41.0 & 18.0 & 8.6 & 6.0 & 5.1 & 4.3 & 18.1 & \multirow[t]{7}{*}{$<0.001$} \\
\hline Within walking distance & 10.3 & 7.7 & 15.4 & 16.2 & 23.1 & 18.0 & 6.8 & 13.9 & \\
\hline Same town/village/city & 6.0 & 12.8 & 27.4 & 35.9 & 32.5 & 34.2 & 21.4 & 24.3 & \\
\hline Another town/village/city & 27.4 & 28.2 & 29.1 & 28.2 & 27.4 & 23.1 & 8.6 & 24.5 & \\
\hline Another country & 12.8 & 9.4 & 10.3 & 10.3 & 9.4 & 9.4 & 9.4 & 10.1 & \\
\hline Do not know where person lives & - & 0.9 & - & 0.9 & 1.7 & 10.3 & 49.6 & 9.0 & \\
\hline Total & 100.0 & 100.0 & 100.0 & 100.0 & 100.0 & 100.0 & 100.0 & 100.0 & \\
\hline \multicolumn{10}{|l|}{ Psychological/emotional distance } \\
\hline Mean & 9.1 & 8.7 & 7.7 & 6.6 & 5.6 & 4.3 & 2.4 & 6.3 & $<0.001$ \\
\hline Median [IQR] & $10[10-8]$ & $9[10-8]$ & $8[9-6]$ & $7[8-5]$ & $5[7-4]$ & $4[6-3]$ & $1[3-1]$ & $7[9-4]$ & \\
\hline Sample (n) & 117 & 117 & 117 & 117 & 117 & 117 & 117 & 819 & \\
\hline
\end{tabular}

Note: Totals may not add up to $100 \%$ due to rounding. 
Table 4: Payment and recipient characteristics

\begin{tabular}{|c|c|c|c|c|c|c|c|c|}
\hline Effect of payment & $\begin{array}{c}\text { (1) } \\
\text { Physical } \\
\text { distance }\end{array}$ & $\begin{array}{c}\text { (2) } \\
\text { Psychological } \\
\text { distance }\end{array}$ & $\begin{array}{c}\text { (3) } \\
\text { Solidarity }\end{array}$ & $\begin{array}{c}(4) \\
\text { Years Known }\end{array}$ & $\begin{array}{c}\text { (5) } \\
\text { Communication }\end{array}$ & $\begin{array}{c}\text { (6) } \\
\text { Family } \\
\text { (probit) }\end{array}$ & $\begin{array}{l}(7) \\
\text { Age }\end{array}$ & $\begin{array}{c}(8) \\
\text { Gender } \\
\text { (probit) }\end{array}$ \\
\hline At mean rank & $\begin{array}{c}0.029 \\
(0.131)\end{array}$ & $\begin{array}{l}-0.242 \\
(0.182)\end{array}$ & $\begin{array}{l}-0.048 \\
(0.058)\end{array}$ & $\begin{array}{c}0.019 \\
(0.139)\end{array}$ & $\begin{array}{c}0.078 \\
(0.182)\end{array}$ & $\begin{array}{c}0.006 \\
(0.049)\end{array}$ & $\begin{array}{c}1.272 \\
(1.003)\end{array}$ & $\begin{array}{l}0.0002 \\
(0.035)\end{array}$ \\
\hline At rank 1 & $\begin{array}{c}-0.726^{* *} \\
(0.282)\end{array}$ & $\begin{array}{c}0.305 \\
(0.276)\end{array}$ & $\begin{array}{c}0.028 \\
(0.038)\end{array}$ & $\begin{array}{c}0.221 \\
(0.216)\end{array}$ & $\begin{array}{l}-0.074 \\
(0.259)\end{array}$ & $\begin{array}{c}0.547 \\
(0.490)\end{array}$ & $\begin{array}{l}-2.052 \\
(2.887)\end{array}$ & $\begin{array}{c}0.183 \\
(0.254)\end{array}$ \\
\hline At rank 2 & $\begin{array}{c}0.259 \\
(0.315)\end{array}$ & $\begin{array}{c}0.046 \\
(0.241)\end{array}$ & $\begin{array}{c}0.051 \\
(0.049)\end{array}$ & $\begin{array}{l}-0.319 \\
(0.292)\end{array}$ & $\begin{array}{l}-0.206 \\
(0.286)\end{array}$ & $\begin{array}{l}-0.944 * \\
(0.566)\end{array}$ & $\begin{array}{c}2.654 \\
(4.698)\end{array}$ & $\begin{array}{l}-0.051 \\
(0.385)\end{array}$ \\
\hline At rank 5 & $\begin{array}{c}0.809 * * * \\
(0.283)\end{array}$ & $\begin{array}{c}-0.624 * * \\
(0.314)\end{array}$ & $\begin{array}{c}0.012 \\
(0.042)\end{array}$ & $\begin{array}{c}0.061 \\
(0.317)\end{array}$ & $\begin{array}{l}-0.020 \\
(0.337)\end{array}$ & $\begin{array}{l}-0.511 \\
(0.504)\end{array}$ & $\begin{array}{c}5.924 \\
(4.224)\end{array}$ & $\begin{array}{c}0.020 \\
(0.315)\end{array}$ \\
\hline At rank 10 & $\begin{array}{l}0.733 * * \\
(0.320)\end{array}$ & $\begin{array}{c}-0.697 * * \\
(0.349)\end{array}$ & $\begin{array}{c}0.027 \\
(0.063)\end{array}$ & $\begin{array}{l}-0.170 \\
(0.335)\end{array}$ & $\begin{array}{c}0.260 \\
(0.374)\end{array}$ & $\begin{array}{l}-0.616 \\
(0.494)\end{array}$ & $\begin{array}{c}4.925 \\
(4.177)\end{array}$ & $\begin{array}{l}-0.452 \\
(0.319)\end{array}$ \\
\hline At rank 20 & $\begin{array}{c}0.869 * * * \\
(0.321)\end{array}$ & $\begin{array}{l}-0.661 \\
(0.428)\end{array}$ & $\begin{array}{l}-0.040 \\
(0.072)\end{array}$ & $\begin{array}{l}-0.028 \\
(0.372)\end{array}$ & $\begin{array}{c}0.190 \\
(0.436)\end{array}$ & $\begin{array}{l}-0.395 \\
(0.482)\end{array}$ & $\begin{array}{c}2.790 \\
(3.920)\end{array}$ & $\begin{array}{l}-0.280 \\
(0.332)\end{array}$ \\
\hline At rank 50 & $\begin{array}{c}1.175^{* * *} * \\
(0.322)\end{array}$ & $\begin{array}{c}-0.948 * \\
(0.511)\end{array}$ & $\begin{array}{c}-0.072 \\
(0.191)\end{array}$ & $\begin{array}{l}-0.269 \\
(0.431)\end{array}$ & $\begin{array}{c}0.497 \\
(0.447)\end{array}$ & $\begin{array}{c}-0.555 \\
(0.522)\end{array}$ & $\begin{array}{c}5.129 \\
(4.070)\end{array}$ & $\begin{array}{c}-0.018 \\
(0.312)\end{array}$ \\
\hline At rank 100 & $1.439 * * *$ & $-0.944 *$ & $-0.509 *$ & -0.692 & 0.346 & -0.510 & 1.845 & -0.471 \\
\hline Observations & 819 & 819 & 819 & 819 & 819 & 819 & 819 & 819 \\
\hline R-squared & 0.209 & 0.604 & 0.493 & 0.369 & 0.384 & - & 0.097 & - \\
\hline
\end{tabular}

Note: Effect of payment is the estimated effect of a discrete change in payment from 0 to 1. 'At mean rank' is the effect evaluated at the sample mean of social distance. Robust standard errors in parentheses, $* * * p<0.01, * * p<0.05, * p<0.1$. Controls for age, gender, poverty status and experimental experience of sender. 
Figure 3: Crossover points, aggregate distribution $(n=117)$

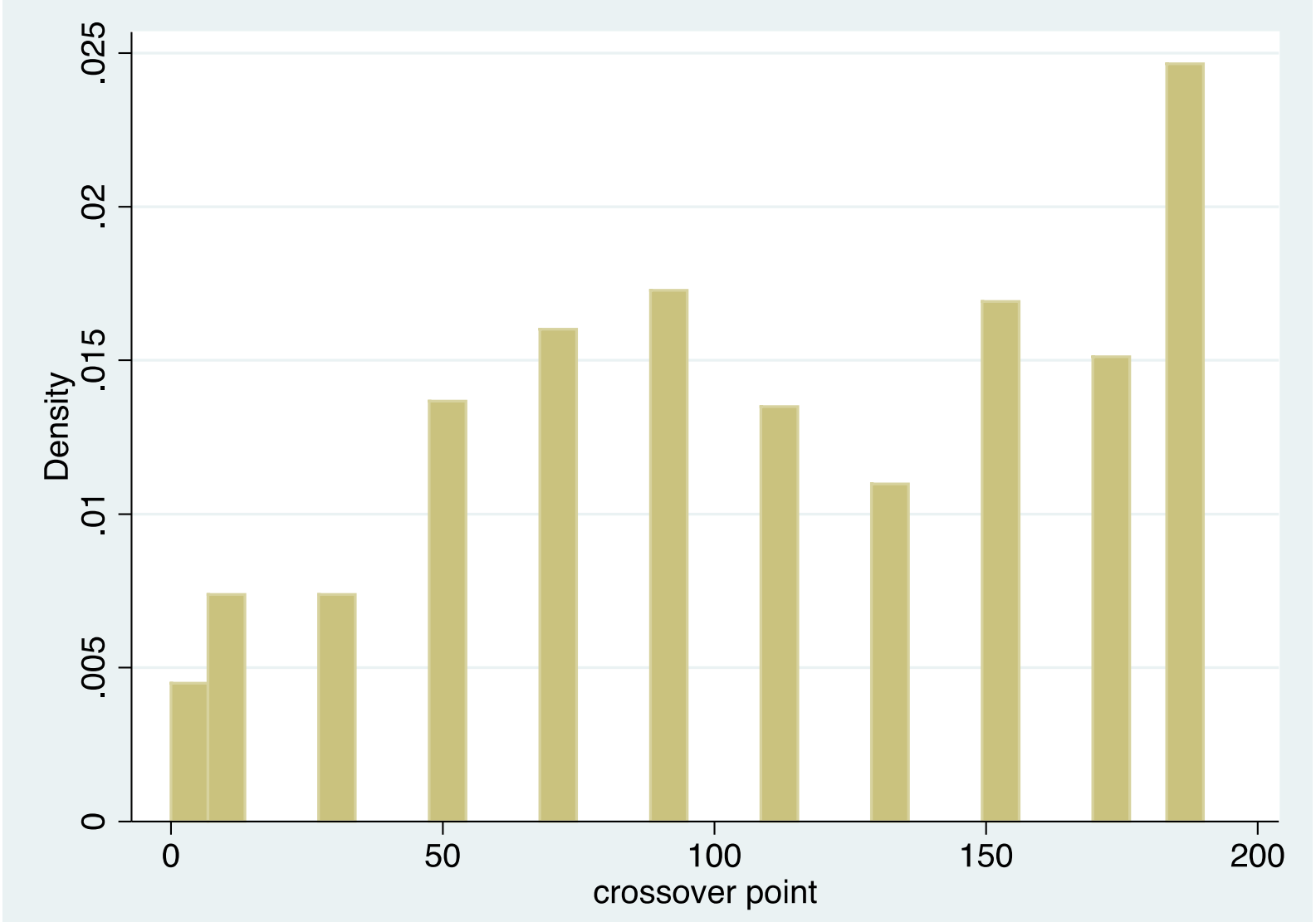

Note: Data for all participants who crossed over multiple times between A and B is included in the above analysis, with the first reported crossover being used as the crossover point. 
Figure 4: Crossover points, by treatment arm $(n=117)$

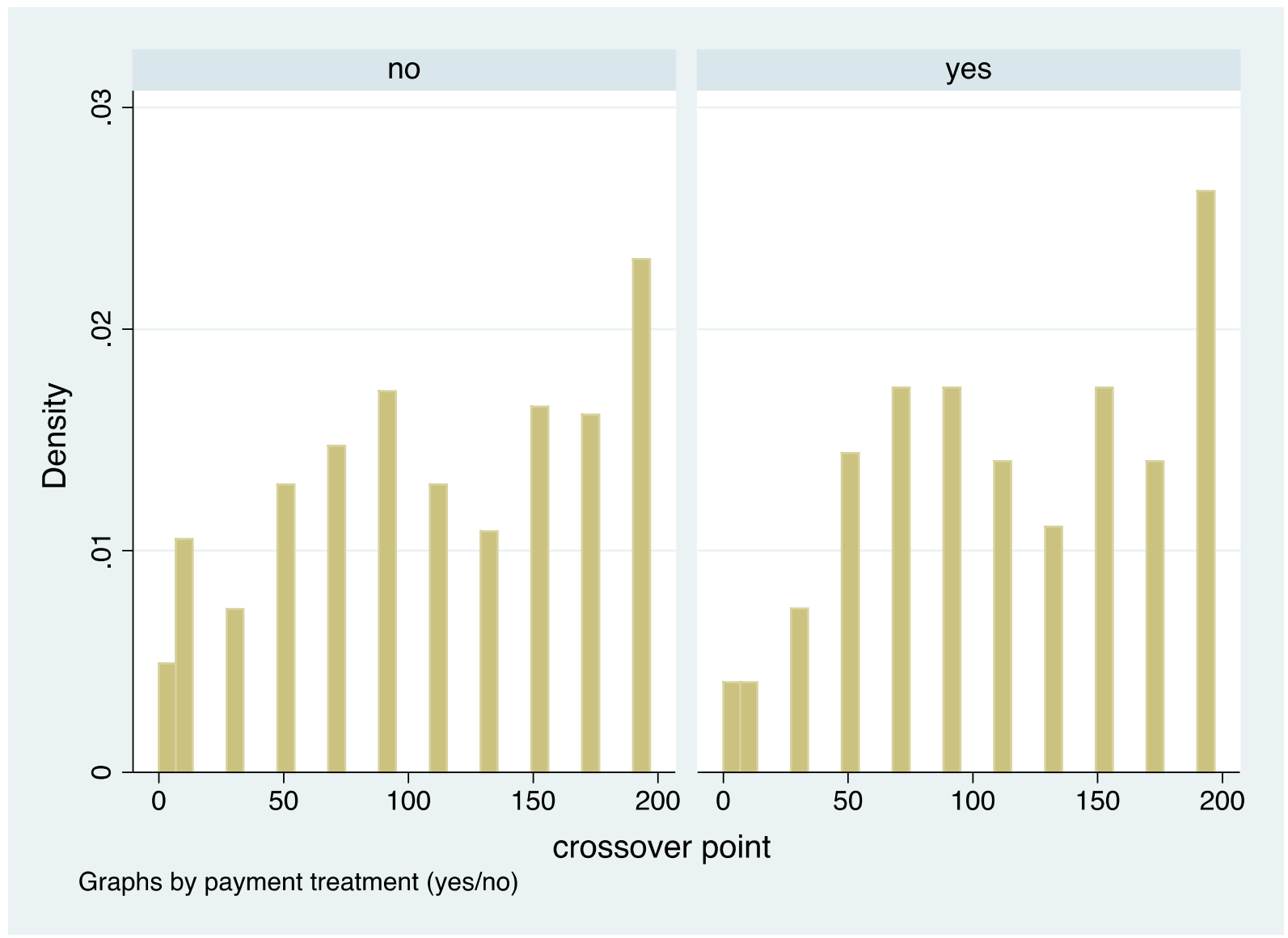

Note: Data for all participants who crossed over multiple times between A and B is included in the above analysis, with the first reported crossover being used as the crossover point. 
Table 5: Mean and median crossover values (Rand), by social distance and treatment arm

\begin{tabular}{|c|c|c|c|c|c|c|c|c|}
\hline \multirow[b]{2}{*}{$\begin{array}{l}\text { Social } \\
\text { distance }\end{array}$} & \multicolumn{4}{|c|}{ Mean } & \multicolumn{4}{|c|}{ Median } \\
\hline & Payment & $\begin{array}{c}\text { Non- } \\
\text { payment }\end{array}$ & p-value & Total & Payment & $\begin{array}{c}\text { Non- } \\
\text { payment }\end{array}$ & p-value & Total \\
\hline 1 & 152.98 & 151.83 & 0.895 & 152.39 & 170 & 170 & 0.836 & 170 \\
\hline 2 & 136.84 & 136.83 & 0.999 & 136.83 & 150 & 150 & 0.836 & 150 \\
\hline 5 & 128.24 & 114.83 & 0.129 & 121.36 & 130 & 130 & 0.682 & 130 \\
\hline 10 & 117.89 & 104.16 & 0.165 & 110.85 & 130 & 90 & 0.318 & 110 \\
\hline 20 & 104.56 & 101.33 & 0.738 & 102.90 & 90 & 100 & 0.635 & 90 \\
\hline 50 & 85.96 & 86.33 & 0.971 & 86.15 & 70 & 90 & 0.318 & 70 \\
\hline 100 & 67.54 & 65.33 & 0.840 & 66.41 & 70 & 50 & 0.635 & 50 \\
\hline Total & 113.43 & 108.66 & 0.242 & 110.98 & 110 & 110 & 0.692 & 110 \\
\hline
\end{tabular}


Table 6a: Regression analysis - crossover values (Rand) - full sample

\begin{tabular}{|c|c|c|c|c|c|}
\hline & $\begin{array}{c}\text { Ordered probit } \\
\text { [pooled] }\end{array}$ & $\begin{array}{c}\text { OLS } \\
\text { [pooled] }\end{array}$ & Random Effects (RE) & Fixed Effects (FE) & $\begin{array}{c}\text { Random Effects (RE) } \\
\text { [mixed] }\end{array}$ \\
\hline \multicolumn{6}{|l|}{ Social distance $($ comparison $=1)$} \\
\hline 2 & $-0.3134 * *$ & $-12.9017 * *$ & $-13.2585^{* * *}$ & $-13.3532 * * *$ & $-13.0132 * * *$ \\
\hline 5 & $-0.5367 * * *$ & $-24.9367 * * *$ & $-25.9768^{* * *}$ & $-26.2491 * * *$ & $-25.5579 * * *$ \\
\hline 10 & $-0.7380 * * *$ & $-36.1666^{* * *}$ & $-37.2859 * * *$ & $-37.5776^{* * *}$ & $-37.0484 * * *$ \\
\hline 20 & $-0.8279 * * *$ & $-41.8904 * * *$ & $-43.4155^{* * *}$ & $-43.8135^{* * *}$ & $-43.1002 * * *$ \\
\hline 50 & $-1.1030 * * *$ & $-56.1197 * * *$ & $-58.1850^{* * *}$ & $-58.7275^{* * *}$ & $-58.0600 * * *$ \\
\hline 100 & $-1.3298 * * *$ & $-65.6197 * * *$ & $-69.4446^{* * *}$ & $-70.4642 * * *$ & $-69.8709 * * *$ \\
\hline Payment & $0.1679 * *$ & $8.1301 * *$ & 8.1141 & & 8.1293 \\
\hline Session & -0.8547 & -3.2659 & -1.5916 & & -0.5472 \\
\hline \multicolumn{6}{|l|}{ Recipient characteristics: } \\
\hline Age & $0.0070^{* * *}$ & $0.3215^{* * *}$ & $0.2636^{* *}$ & $0.2486^{* *}$ & $0.2702 * * *$ \\
\hline Gender $($ comparison $=$ male $)$ & 0.0608 & 2.6978 & 3.2959 & 3.4403 & $4.7794 *$ \\
\hline Family member & 0.1078 & 4.9321 & 2.1174 & 1.4086 & 2.2053 \\
\hline Solidarity index (MCA) & $0.1342 * *$ & $6.6737 * *$ & $5.5466^{*}$ & $5.2397 *$ & $5.0705 *$ \\
\hline \multicolumn{6}{|l|}{ Sender characteristics: } \\
\hline Age & $0.0770 * * *$ & $3.8275^{* * *}$ & $3.8505^{* * *}$ & & $3.5683 * *$ \\
\hline Gender (comparison = male) & $0.1275^{*}$ & $7.0129 *$ & 6.9092 & & 4.4593 \\
\hline Household poverty ranking & -0.1292 & -0.6047 & -0.7362 & & -1.7987 \\
\hline Experimental experience (yes) & $0.1961 * * *$ & $10.7436^{* * *}$ & $10.7354 * * *$ & & $9.1926^{* * *}$ \\
\hline Sample (n) & 819 & 819 & 819 & 819 & 819 \\
\hline Wald chi2 / F-test & $181.30^{* * *}$ & $19.70 * * *$ & $240.46^{* * *}$ & $17.19 * * *$ & $291.69 * * *$ \\
\hline (Pseudo) $\mathrm{R}^{2}$ & 0.0631 & 0.2675 & 0.2668 & 0.2334 & \\
\hline Breusch \& Pagan LM test & & & $336.80 * * *$ & & \\
\hline
\end{tabular}


Table 6b: Regression analysis - crossover values (Rand) - restricted sample

\begin{tabular}{|c|c|c|c|c|c|}
\hline & $\begin{array}{l}\text { Ordered probit } \\
\text { [pooled] }\end{array}$ & $\begin{array}{c}\text { OLS } \\
\text { [pooled] }\end{array}$ & Random Effects (RE) & Fixed Effects (FE) & $\begin{array}{c}\text { Random Effects (RE) } \\
\text { [mixed] }\end{array}$ \\
\hline \multicolumn{6}{|l|}{ Social distance $($ comparison $=1)$} \\
\hline 2 & $-0.4477 * *$ & $-17.2084 * *$ & $-18.0865^{* * * *}$ & $-18.2226^{* * *}$ & $-17.9496^{* * *}$ \\
\hline 5 & $-0.6903 * * *$ & $-30.0039^{* * *}$ & $-31.8945^{* * *}$ & $-32.2328 * * *$ & $-31.4826^{* * *}$ \\
\hline 10 & $-0.9671 * * *$ & $-42.9006^{* * *}$ & $-45.3559^{* * *}$ & $-45.7946 * * *$ & $-44.4094 * * *$ \\
\hline 20 & $-1.0194 * * *$ & $-45.3674^{* * *}$ & $-48.5896^{* * *}$ & $-49.1647 * * *$ & $-47.5614^{* * *}$ \\
\hline 50 & $-1.3059 * * *$ & $-58.2677^{* * *}$ & $-61.7451^{* * *}$ & $-62.3624 * * *$ & $-59.6772 * * *$ \\
\hline 100 & $-1.5372 * * *$ & $-66.6980^{* * *}$ & $-70.1545^{* * *}$ & $-70.7655^{* * *}$ & $-65.1077 * * *$ \\
\hline Payment & 0.0894 & 2.9703 & 3.3074 & & 0.9027 \\
\hline Session & -0.2155 & -9.3466 & -5.4753 & & -3.3441 \\
\hline \multicolumn{6}{|l|}{ Recipient characteristics: } \\
\hline Age & $0.0078^{* *}$ & $0.3313^{* *}$ & 0.2014 & 0.1784 & 0.1624 \\
\hline Gender $($ comparison $=$ male $)$ & 0.1023 & 3.7081 & 4.1264 & 4.1888 & 5.3746 \\
\hline Family member & 0.0187 & 0.7988 & -5.9888 & -7.1981 & -3.1313 \\
\hline Solidarity index (MCA) & 0.1008 & 4.8763 & $4.8181^{*}$ & $4.8112 *$ & $6.7696^{* * *}$ \\
\hline \multicolumn{6}{|l|}{ Sender characteristics: } \\
\hline Age & $0.0402 *$ & $1.9244^{* *}$ & 2.0932 & & $2.9088^{*}$ \\
\hline Gender $($ comparison $=$ male $)$ & $0.2429^{* *}$ & $11.6026^{* *}$ & 11.9984 & & 12.9026 \\
\hline Household poverty ranking & $0.2404 * * *$ & $11.7682 * * *$ & $11.5214^{*}$ & & $10.8479^{*}$ \\
\hline Experimental experience (yes) & $0.4015 * * *$ & $18.8617^{* * *}$ & $18.6841^{* * *}$ & & $15.9046^{* * *}$ \\
\hline Sample (n) & 406 & 406 & 406 & 406 & 406 \\
\hline Wald chi2 / F-test & $122.85^{* * *}$ & $14.65^{* * *}$ & $236.84 * * *$ & $12.30^{* * *}$ & $208.54 * * *$ \\
\hline (Pseudo) $\mathrm{R}^{2}$ & 0.0779 & 0.3141 & 0.3115 & 0.2428 & \\
\hline Breusch \& Pagan LM test & & & $238.18 * * *$ & & \\
\hline
\end{tabular}


Figure 5: Difference in crossover points, by social distance

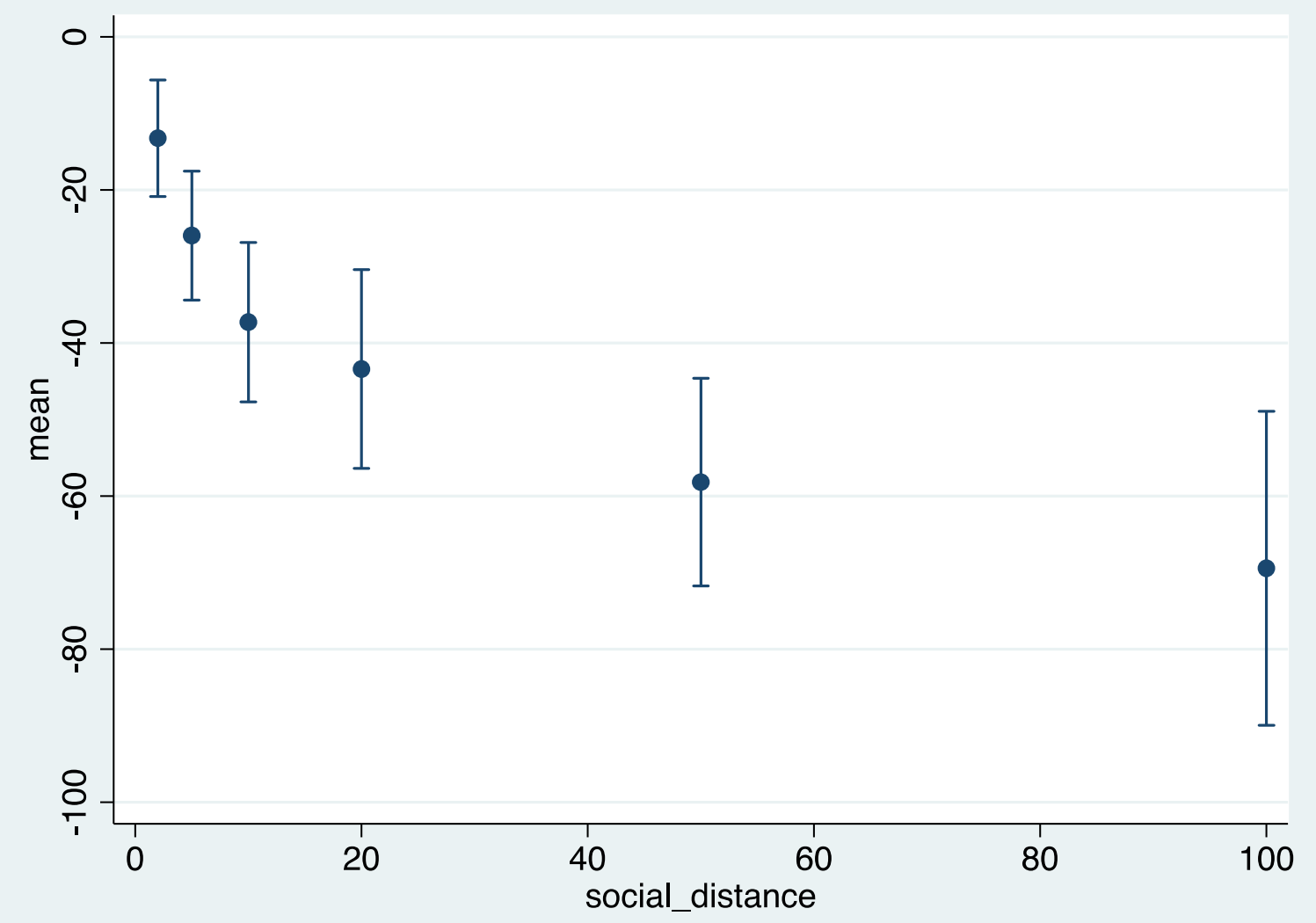

Note: The graph plots the coefficients from the mixed Random Effects (RE) regression model (Table 5). 
Figure 6: Crossover point, by relation

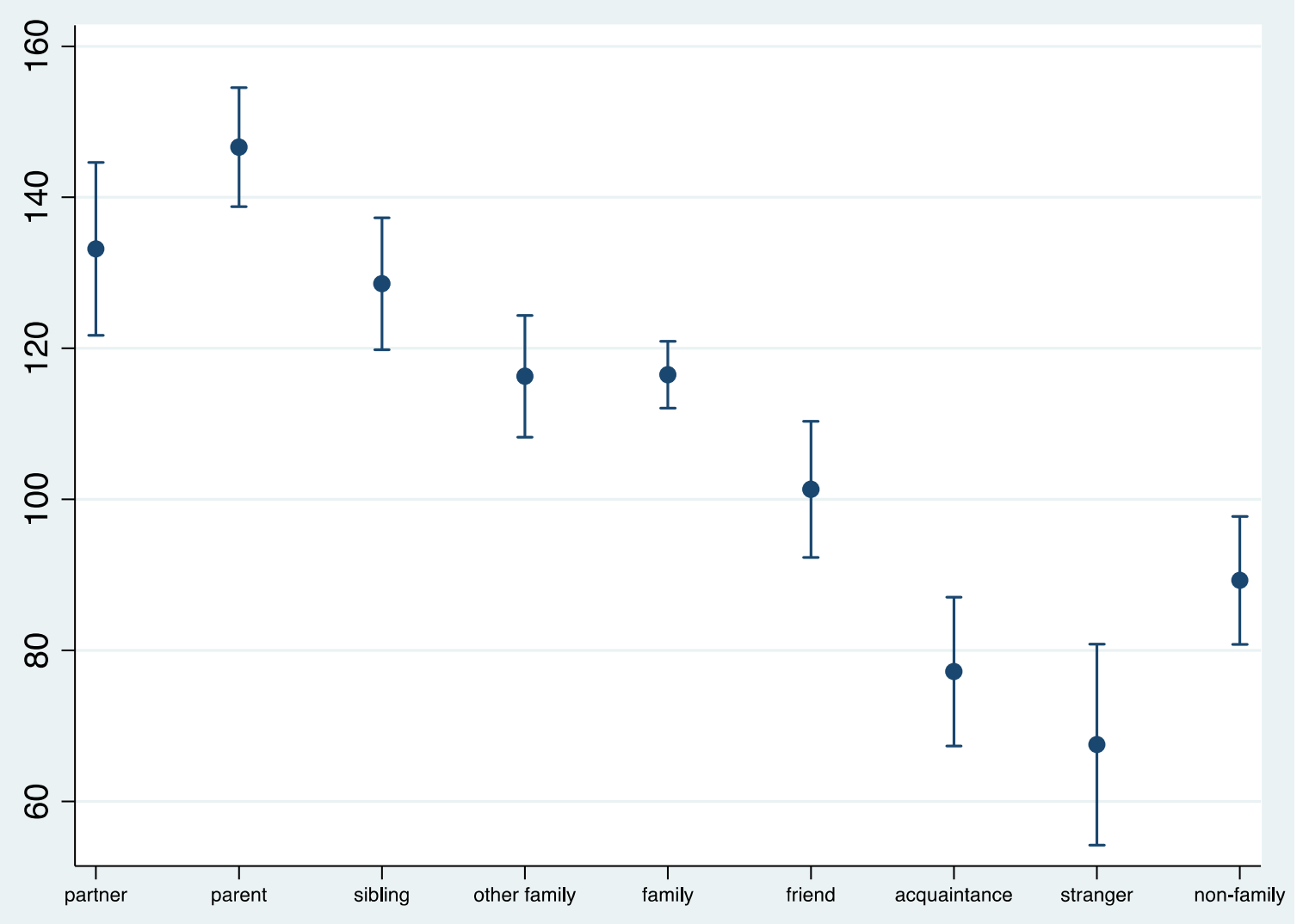


Figure 7: Social discounting rate $\left(\mathrm{k}^{\prime}\right)$, by treatment arm

(a) Restricted sample

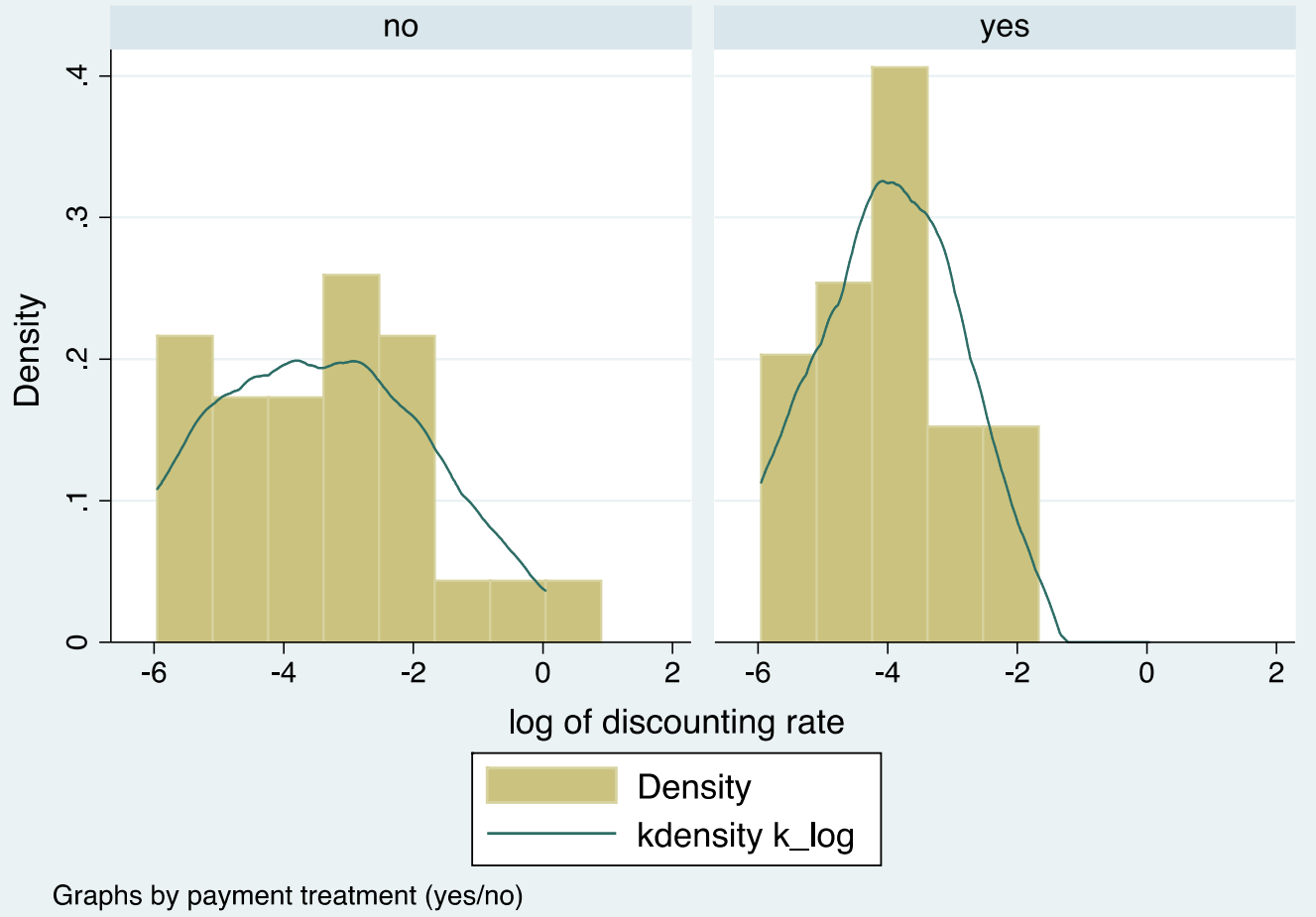

\section{(b) Full sample}

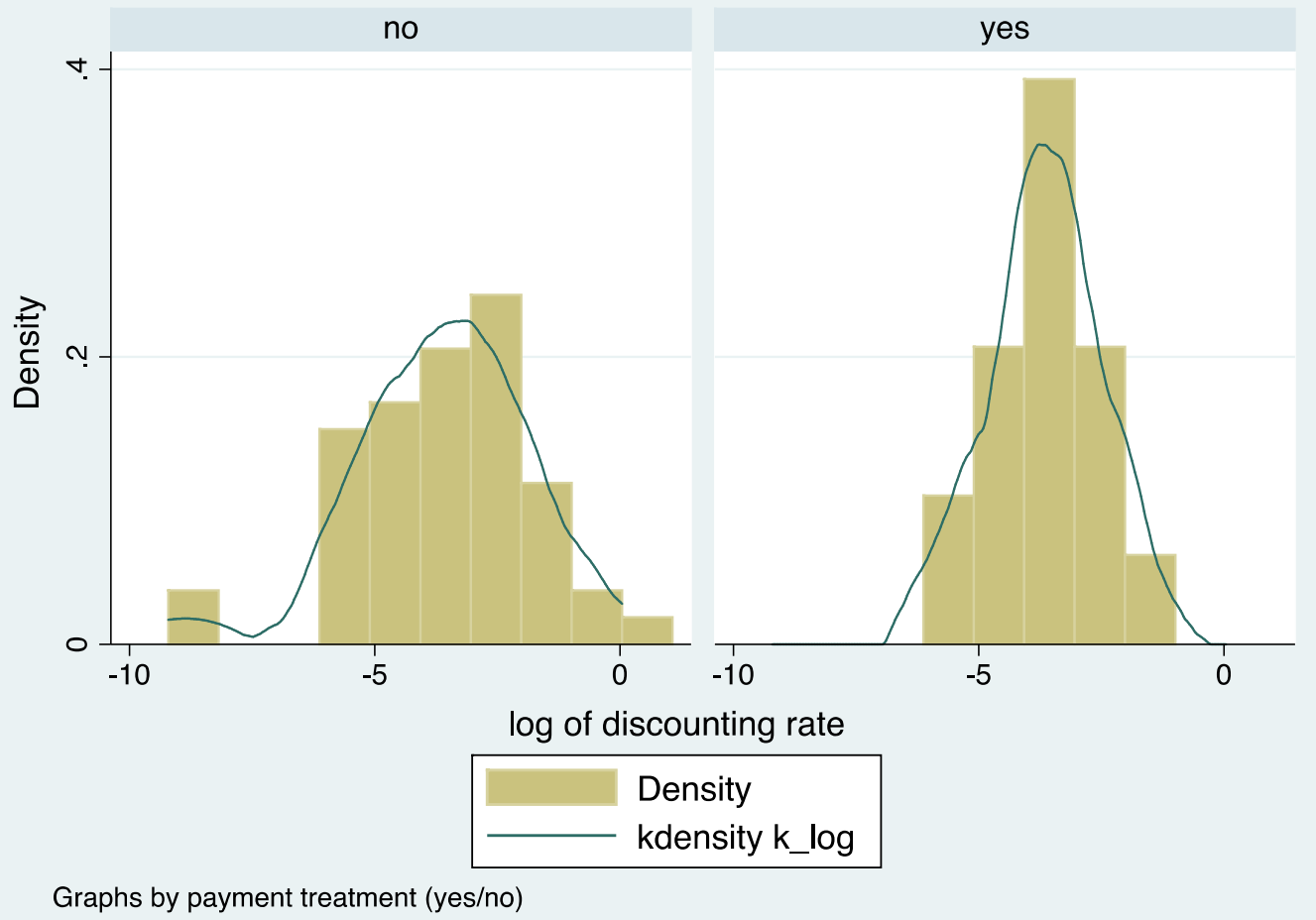


Figure 8: Hyperbolic social discounting functions, by treatment arm

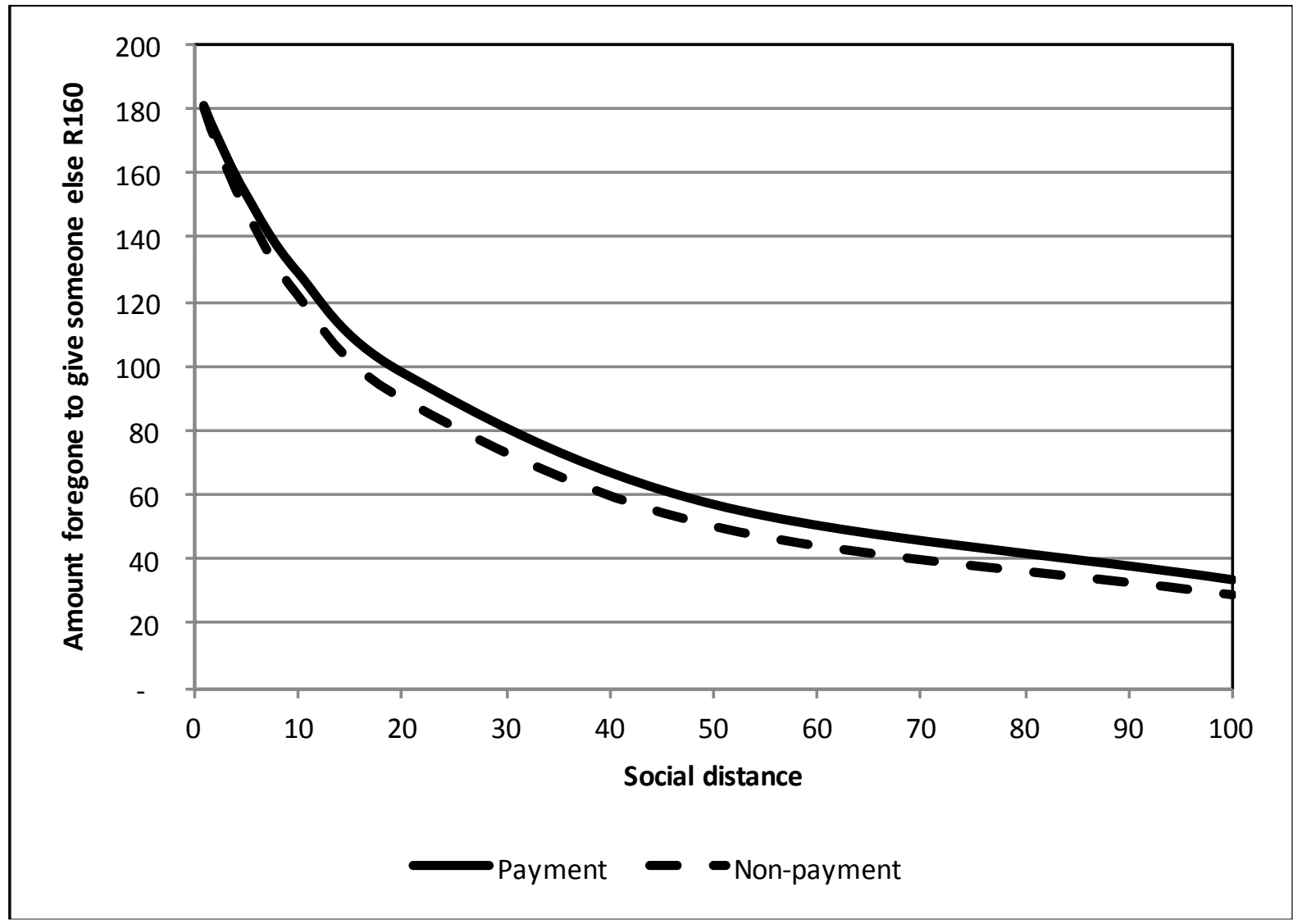

Note: Data for participants who crossed over multiple times between A and B are included in the analysis, with the first reported cross-over used as the cross-over point. 
Table 7: Regression analysis - social discounting rate $\left(\mathrm{k}^{\prime}\right)$

\begin{tabular}{|c|c|c|c|c|}
\hline & \multicolumn{2}{|c|}{ Restricted Sample } & \multicolumn{2}{|c|}{ Full Sample } \\
\hline & Tobit $\left(k^{\prime}\right)$ & OLS $\left(\log k^{\prime}\right)$ & Tobit $\left(k^{\prime}\right)$ & OLS $\left(\log k^{\prime}\right)$ \\
\hline \multicolumn{5}{|l|}{ Treatment: } \\
\hline Payment & $-0.0988^{*}$ & -0.5676 & $-0.0513^{*}$ & 0.0322 \\
\hline \multicolumn{5}{|l|}{ Design: } \\
\hline Session & 0.0531 & 0.1546 & -0.0058 & -0.4184 \\
\hline \multicolumn{5}{|l|}{ Sender characteristics: } \\
\hline Age & 0.0009 & 0.0364 & $-0.0068 * *$ & -0.0703 \\
\hline Gender $($ comparison $=$ male $)$ & -0.0131 & 0.0608 & -0.0149 & 0.0873 \\
\hline Household poverty ranking & -0.0038 & -0.3614 & 0.0072 & -0.2250 \\
\hline Experimental experience (yes) & $-0.1165^{* *}$ & $-2.0540 * * *$ & $-0.0468^{*}$ & -0.2608 \\
\hline Sample (n) & 57 & 50 & 116 & 99 \\
\hline F-test & $2.54 * *$ & - & $1.88^{*}$ & 0.91 \\
\hline (Pseudo) $\mathrm{R}^{2}$ & 0.3202 & 0.1193 & 0.0794 & 0.0470 \\
\hline
\end{tabular}


Figure 9: Area under the curve (AUC), by treatment arm

\section{(a) Restricted sample}

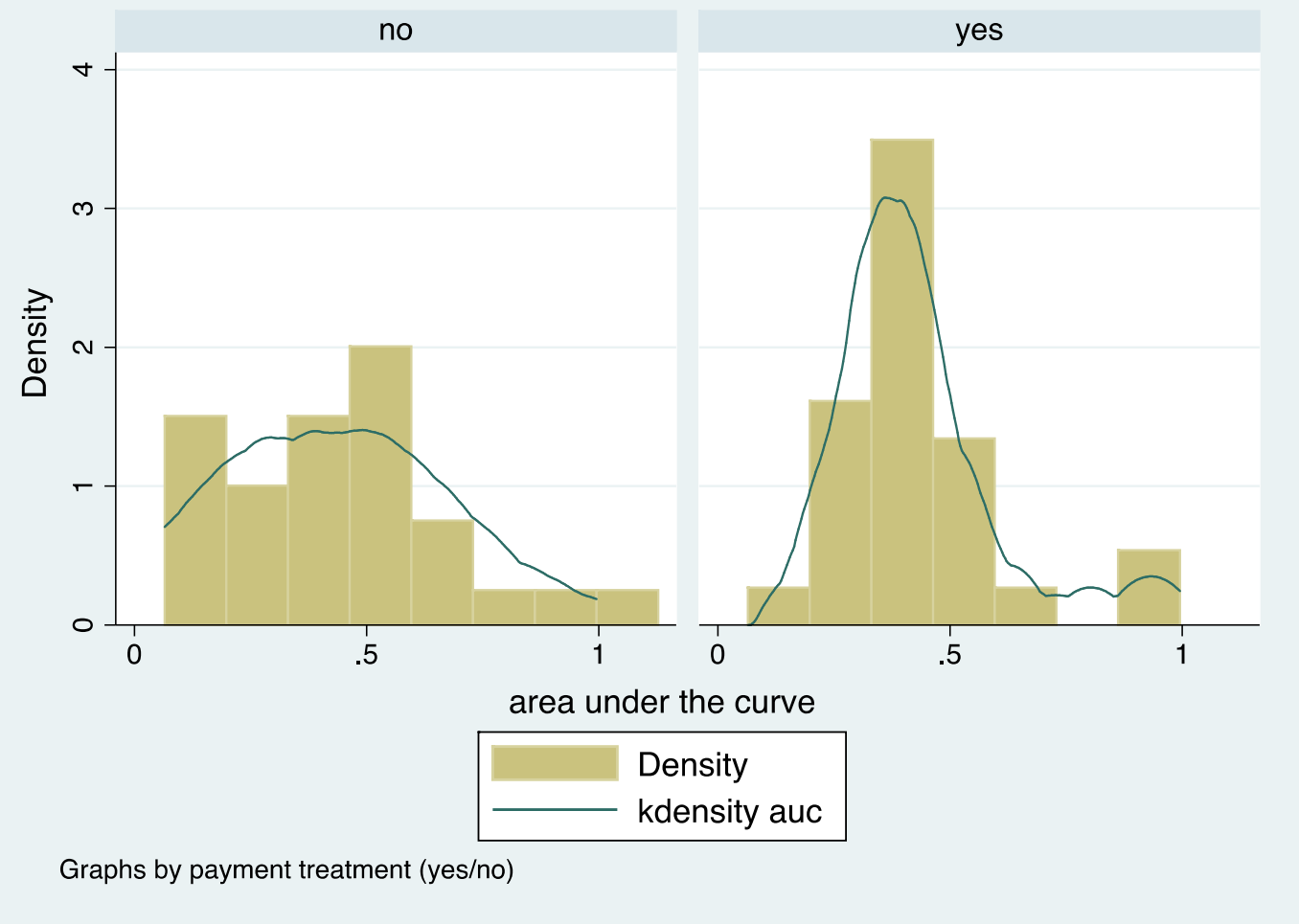

(b) Full sample

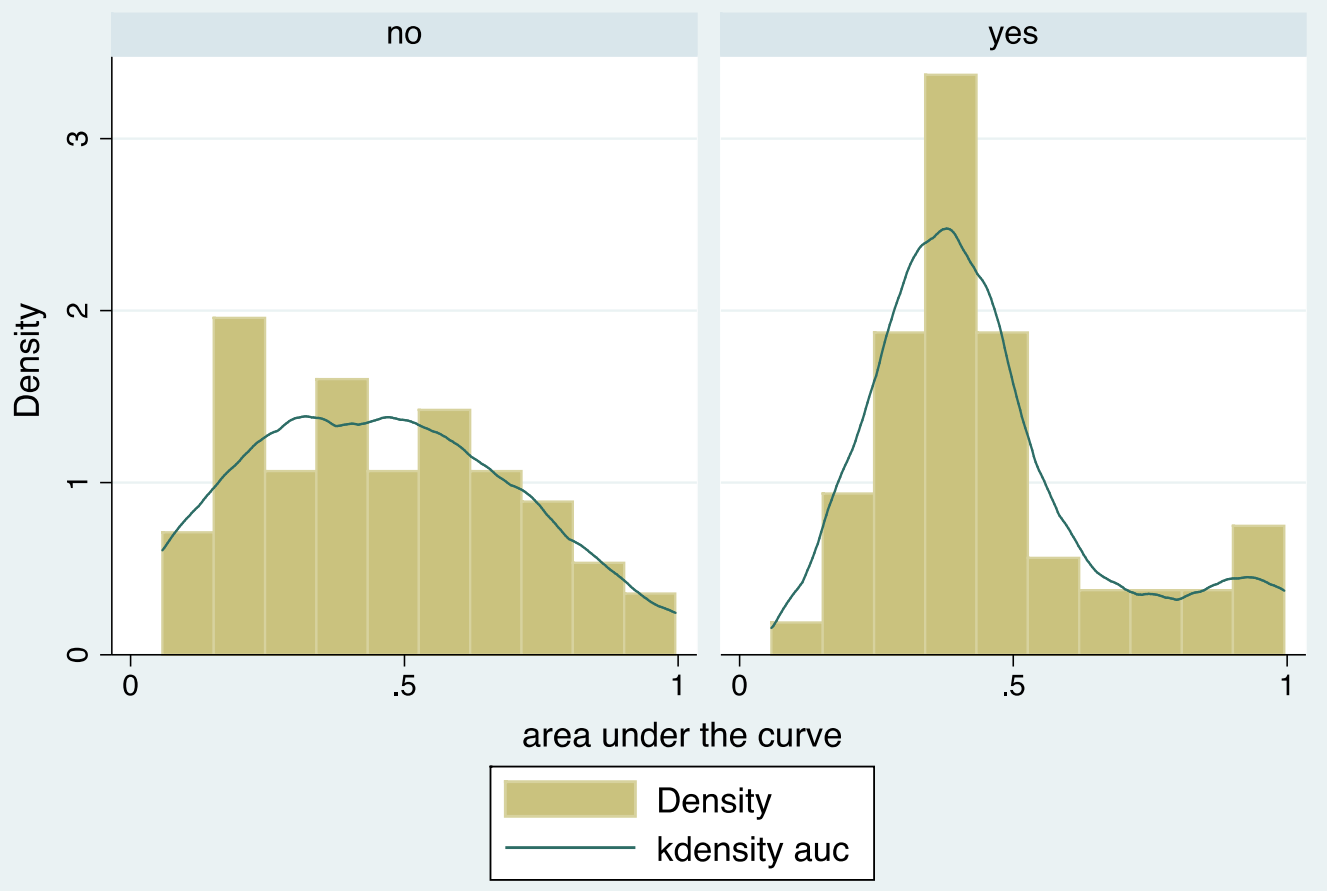

Graphs by payment treatment (yes/no) 
Figure 10: Scatterplot - discounting rates $\left(\mathrm{k}^{\prime}\right)$ and area under the curve (AUC)

(a) Restricted sample

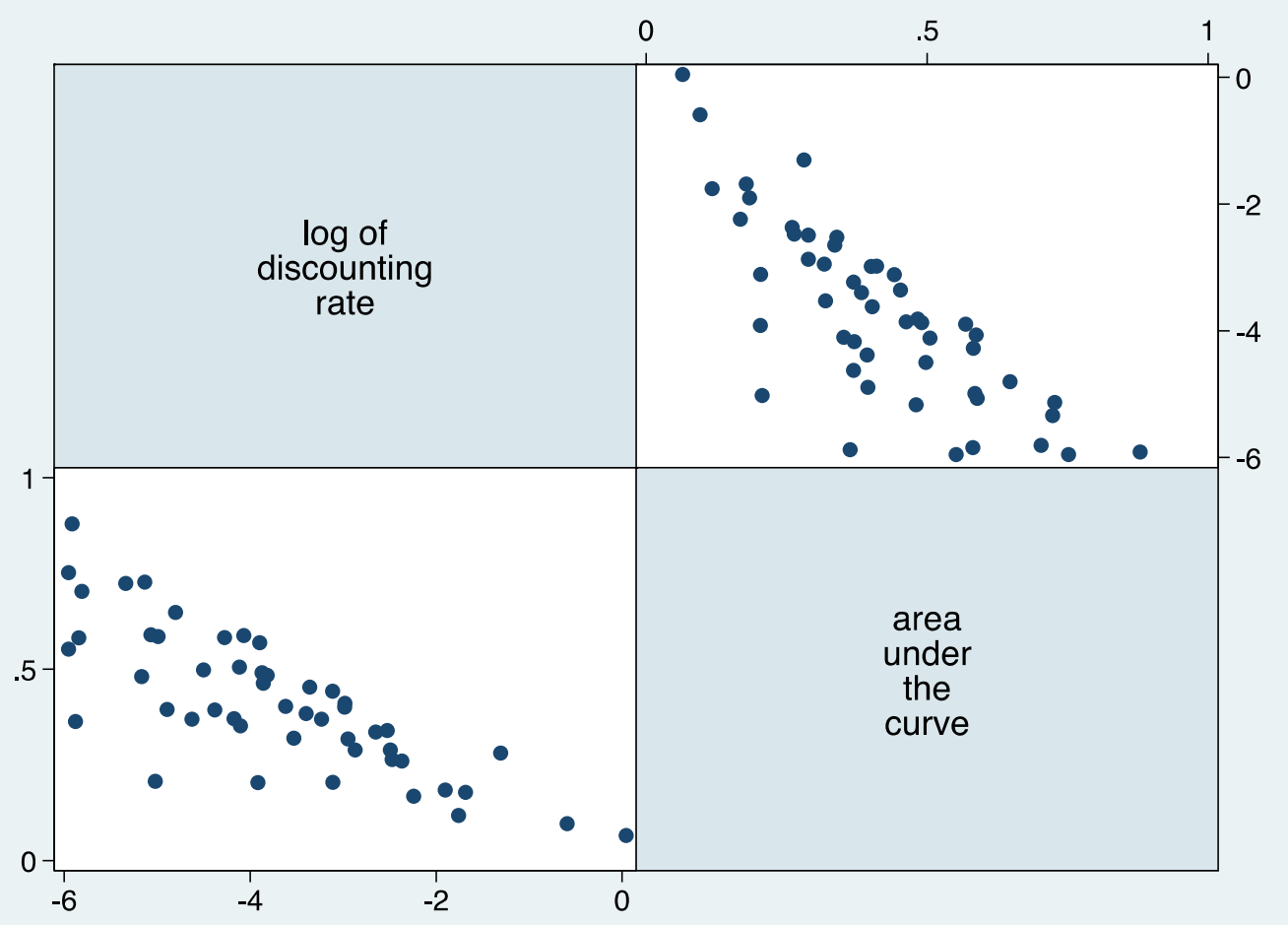

(b) Full sample

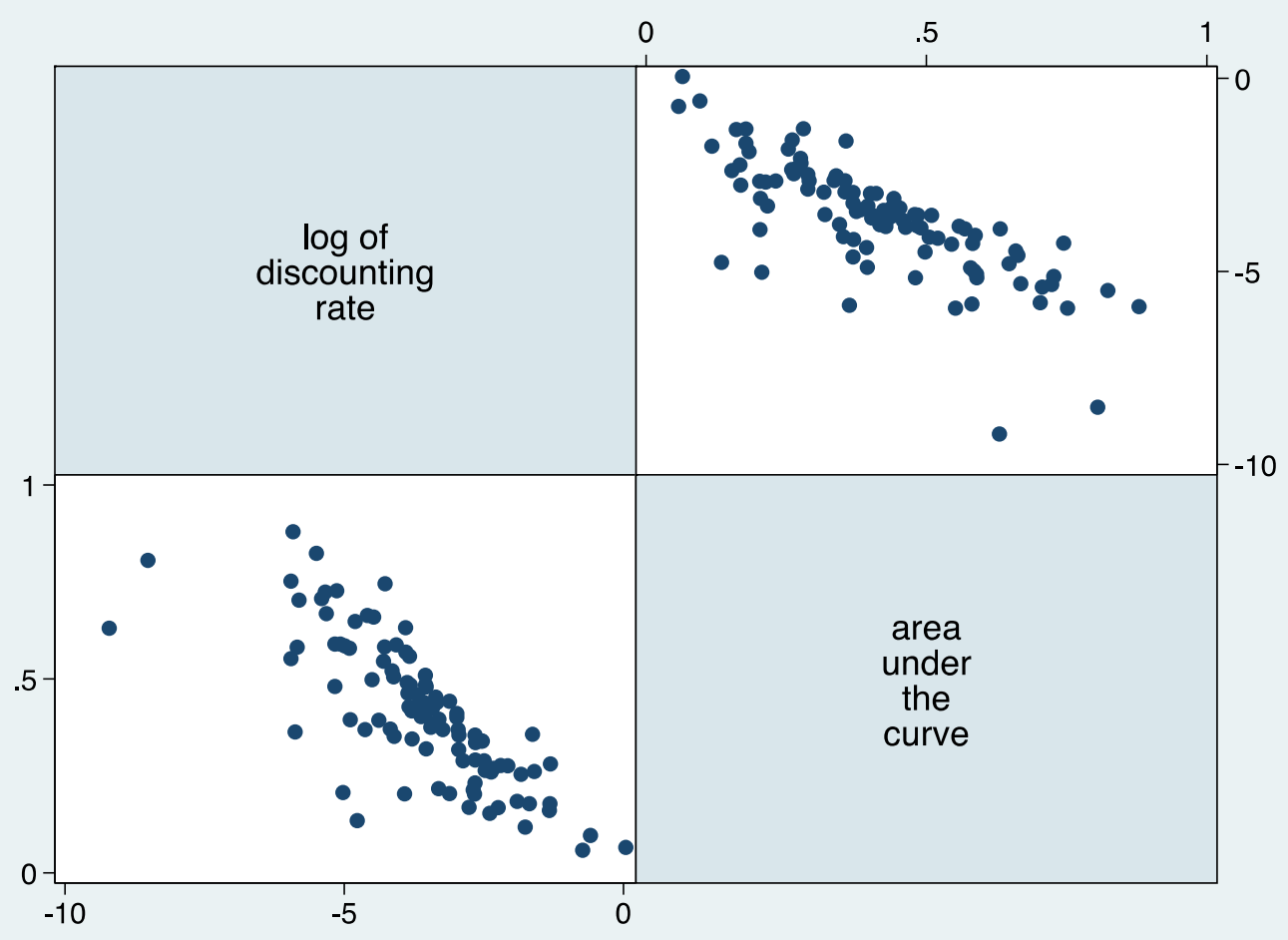


Table 8: Regression analysis - area under the curve (AUC)

\begin{tabular}{|l|c|c|}
\hline & Restricted Sample & Full Sample \\
\hline Treatment: & & 0.0078 \\
\hline Payment & & \\
\hline & & \\
\hline Design: & & 0.0135 \\
\hline Session & -0.0255 & \\
\hline & & $0.0258^{* * *}$ \\
\hline Sender characteristics: & & 0.0449 \\
\hline Age & 0.0068 & 0.0005 \\
\hline Gender (comparison = male) & 0.0654 & $0.0784^{* * *}$ \\
\hline Household poverty ranking & 0.0473 & 117 \\
\hline Experimental experience (yes) & $0.1195^{* * *}$ & $12.83^{* * *}$ \\
\hline & & 0.1084 \\
\hline Sample (n) & 58 & $13.68^{* * *}$ \\
\hline F-test & 0.1485 & \\
\hline (Pseudo) R & & \\
\hline
\end{tabular}


Annexure A1: Social Discounting Task (SDT) - introduction and practice table

\section{SOCIAL DISCOUNTING TASK}

First, let us look at an example of how the task works and how we will calculate your earnings from the particular task.

The following experiment asks you to imagine that you have made a list of the 100 people closest to you in the world ranging from your dearest friend or relative at position \#1 to a mere acquaintance at $\# 100$. The person at number one would be someone you know well and is your closest friend or relative. The person at \#100 might be someone you recognize and encounter but perhaps you may not even know their name.

You do not have to physically create the list- just imagine that you have done so.

For example, imagine the following choices between an amount of money for you and an amount for person \#75 on the list. Circle A or B on the right hand side to indicate which option you would choose in EACH line,. Please note that there is no wrong or right answer, simply indicate whether you would choose A or B in each row.

\begin{tabular}{|c|c|c|c|c|}
\hline & OPTION A: & OPTION B: & \multicolumn{2}{|c|}{ CIRCLE } \\
\hline 1. & R90 for you alone & R80 for person $\# 75$ on the list & $\mathrm{A}$ & $\mathrm{B}$ \\
\hline 2. & R80 for you alone & R80 for person \#75 on the list & A & $\mathrm{B}$ \\
\hline 3. & R70 for you alone & R80 for person \#75 on the list & $\mathrm{A}$ & $\mathrm{B}$ \\
\hline 4. & R60 for you alone & $\mathrm{R} 80$ for person $\# 75$ on the list & $\mathrm{A}$ & $\mathrm{B}$ \\
\hline 5. & R50 for you alone & R80 for person $\# 75$ on the list & $\mathrm{A}$ & $\mathrm{B}$ \\
\hline 6. & R40 for you alone & R80 for person $\# 75$ on the list & $\mathrm{A}$ & $\mathrm{B}$ \\
\hline 7. & R30 for you alone & R80 for person $\# 75$ on the list & $\mathrm{A}$ & $\mathrm{B}$ \\
\hline 8. & R20 for you alone & R80 for person $\# 75$ on the list & $\mathrm{A}$ & $\mathrm{B}$ \\
\hline 9. & R10 for you alone & R80 for person $\# 75$ on the list & $\mathrm{A}$ & $\mathrm{B}$ \\
\hline 10. & R0 for you alone & R80 for person $\# 75$ on the list & A & B \\
\hline
\end{tabular}

Row selected for payment:

Option (A/B):

Please complete the exercise table now.

Do you have any questions? 
Annexure A2: Social Discounting Task (SDT) - standard table

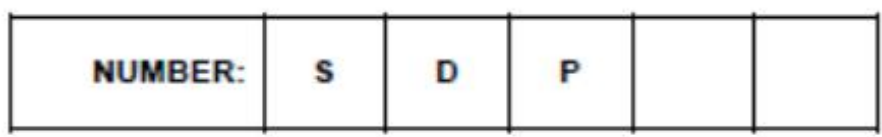

\section{SOCIAL DISCOUNTING TASK (continued)}

Imagine you made a list of the 100 people closest to you in the world ranging from your dearest friend or relative at $\# 1$ to a mere acquaintance at $\# 100$.

Now imagine the following choices between an amount of money for you and an amount for person \#1 on the list. Circle A or B on the right hand side to indicate which option you would choose in EACH line.

\begin{tabular}{|l|l|l|c|c|}
\hline & OPTION A: & OPTION B: & \multicolumn{2}{|c|}{ CIRCLE } \\
\hline 1. & R180 for you alone & R160 for person \#1 on the list & A \\
\hline 2. & R160 for you alone & R160 for person \#1 on the list & A & B \\
\hline 3. & R140 for you alone & R160 for person \#1 on the list & B \\
\hline 4. & R120 for you alone & R160 for person \#1 on the list & A & B \\
\hline 5. & R100 for you alone & R160 for person \#1 on the list & A & B \\
\hline B. & R80 for you alone & R160 for person \#1 on the list & B \\
\hline 7. & R60 for you alone & R160 for person \#1 on the list & A & B \\
\hline 8. & R40 for you alone & R160 for person \#1 on the list & A & B \\
\hline 8. & R20 for you alone & R160 for person \#1 on the list & A & B \\
\hline 10. & R0 for you alone & R160 for person \#1 on the list & A & B \\
\hline
\end{tabular}

Row selected for payment:

Option (A/B):

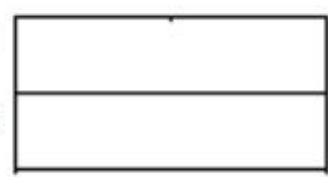


Annexure A3: Social Discounting Task (SDT) - treatment script

Payment:

You will complete seven of these tables.

First, we will randomly select one of these tables using a dice.

Then, one of the ten rows in the selected table will be selected randomly using a ten-sided dice.

The selected decision will be implemented, i.e. we will pay you the actual amount of money for real for the choice you have made.

For example, looking at the above exercise table and assuming this table was selected for payment, if row 3 was selected randomly for payment and you had chosen option $B$, then we will pay person \#75 on your list R80 (we will collect this information from you later). If you had chosen option A, we will pay you R70.

If row 8 was selected, and you chose option $A$, we will pay you R20. If you chose $B$, we will pay person \#75 on your list R80.

Next you will be asked to answer a series of questions about this particular person at a given social distance. In each case, imagine the person who best fits the specific position (\#1 to $\# 100)$ and answer each question.

Do you have any questions?

Let us play the first table now.

Please remember that there is no wrong or right answer, simply indicate whether you would choose $\mathrm{A}$ or $\mathrm{B}$ in each row.

Please take care when completing the tables as the values are different from those in the exercise table. 
Annexure A4: Social discounting - recipient questionnaire

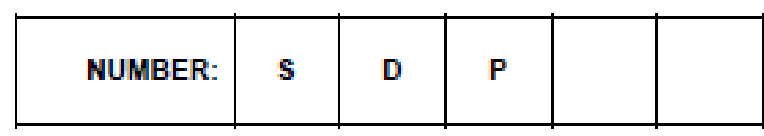

\section{SOCIAL DISCOUNTING TASK (continued)}

Now we would appreciate it if you can provide us with more information on person \#1. For

Person \#1 on your list, please indicate which category best fits your relationship with that person by checking ONE box ONLY.

Wife/Husband
Mother/Father
Sister/Brother (sibling)
Uncle/Aunt
Niece/Nephew
Grandparent
Other family
Other:
(please specify)

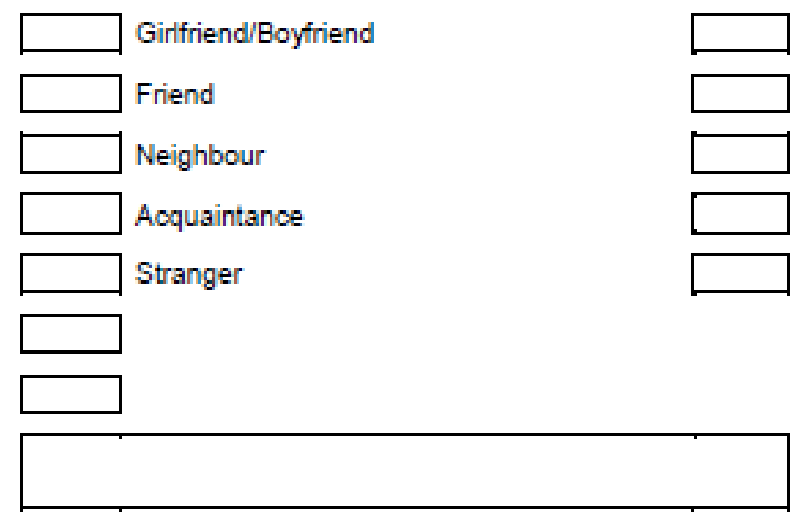

In addition, please provide the following information for person \#1:

Age (approximately):

Gender (circle ONE option ONLY):

How long have you known this person?

Note: Mark ONE option ONLY.

How often do you communicate with this person?

Note: Mark ONE option ONLY.

How far does this person live from you?

Note: Mark ONE option ONLY.

On a ten-point scale, at an emotional and psychological level, how close do you perceive yourself to be to this particular person?

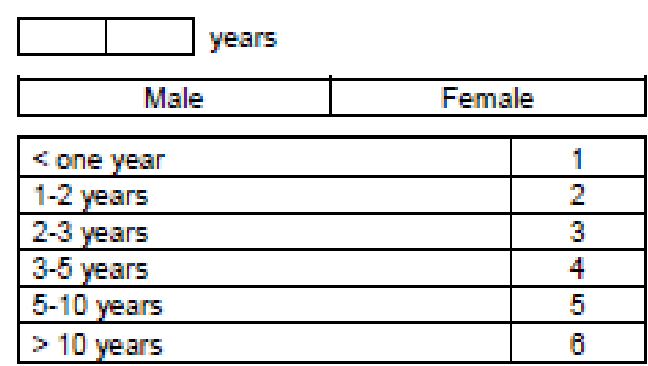

\begin{tabular}{|l|l|}
\hline Daily & 1 \\
\hline A few times a week & 2 \\
\hline Once a week & 3 \\
\hline A few times a month & 4 \\
\hline Once a month & 5 \\
\hline A few times a year & 6 \\
\hline Less frequently & 7 \\
\hline I have no contact with this person & 8 \\
\hline
\end{tabular}

\begin{tabular}{|l|c|}
\hline We live together & 1 \\
\hline Within walking distance & 2 \\
\hline In the same town/city/village & 3 \\
\hline In another town/city/village & 4 \\
\hline In another country & 5 \\
\hline I do not know where this person lives & 6 \\
\hline
\end{tabular}

Not close at all

Extremely close

\begin{tabular}{|l|l|l|l|l|l|l|l|l|l|}
\hline 1 & 2 & 3 & 4 & 5 & 6 & 7 & 8 & 9 & 10 \\
\hline
\end{tabular}


Annexure A5: Social discounting - post-experimental subject questionnaire

\section{SOCIO-DEMOGRAPHIC QUESTIONNAIRE}

Please provide us with the following information - please note that all information will be kept confidential and nobody else will know what you have written:

1. Age:

2. Gender:

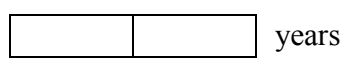

Note: Circle ONE option ONLY.

3. Race:

\begin{tabular}{|l|l|l|l|}
\hline African/Black $=1$ & Coloured $=2$ & Asian/Indian $=3$ & White $=4$ \\
\hline
\end{tabular}

Note: Circle ONE option ONLY.

4. Home language:

\begin{tabular}{|c|c|c|c|c|c|}
\hline Afrikaans $=1$ & English $=2$ & IsiNdebele $=3$ & IsiXhosa $=4$ & IsiZulu $=5$ & Sepedi $=6$ \\
\hline Sesotho $=7$ & Setswana $=8$ & Siswati $=9$ & Tshivenda $=10$ & Xitsonga $=11$ & Other $=12$ \\
\hline
\end{tabular}

Note: Circle ONE option ONLY.

5. Faculty:

\begin{tabular}{|c|c|c|c|c|c|c|}
\hline $\begin{array}{c}\text { Economic } \\
\text { and } \\
\begin{array}{c}\text { Management } \\
\text { Sciences } \\
=1\end{array}\end{array}$ & Education & $\begin{array}{c}\text { Health } \\
\text { Sciences }\end{array}$ & Humanities & Law & $\begin{array}{c}\text { Natural and } \\
\text { Agricultural } \\
\text { Sciences } \\
=6\end{array}$ & $\begin{array}{c}\text { Theology } \\
=7\end{array}$ \\
\hline
\end{tabular}

Note: Circle ONE option ONLY.

6. Imagine a six-step ladder where the poorest in South Africa stand at the bottom (the first step) and the richest people in South Africa stand on the highest step (the sixth step). On which step are your household today?

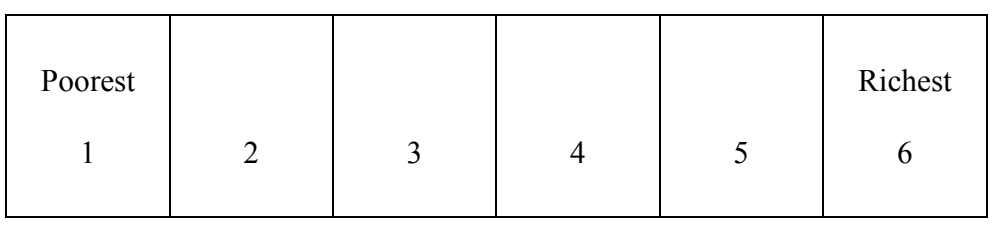

Note: Circle ONE option ONLY.

7. How will you describe your financial situation today? (i.e. the status of your personal finances)

Note: Mark ONE option ONLY.

\begin{tabular}{|l|l|}
\hline Very broke & 1 \\
\hline Broke & 2 \\
\hline Neither & 3 \\
\hline In good shape & 4 \\
\hline In very good shape & 5 \\
\hline
\end{tabular}

8. Have you applied to UFS for financial aid?

\begin{tabular}{l|l} 
Yes $=1$ & No $=0$
\end{tabular}

Note: Circle ONE option ONLY.

9. Were you awarded financial aid from UFS?

\begin{tabular}{l|l} 
Yes $=1$ & No $=0$
\end{tabular}

Note: Circle ONE option ONLY.

10. Have you previously participated in any experiment of this nature?

\begin{tabular}{l|l} 
Yes $=1$ & No $=0$
\end{tabular}

Note: Circle ONE option ONLY. 